\title{
SIMULATION METHODS AND SOFTWARE ENGINEERING PRINCIPLES FOR THE ANALYSIS OF COST-EFFECTIVE DISEASE PREVENTION
}

\author{
by \\ Arman Hamzehlou Kahrizi \\ Bachelor of Science in Electronic Commerce, Staffordshire University, 2011
}

\author{
A thesis \\ presented to Ryerson University \\ in partial fulfillment of the \\ requirements for the degree of \\ Master of Science in Management \\ in the program of \\ Master of Science in Management
}

Toronto, Ontario, Canada, 2020

(C) Arman Hamzehlou Kahrizi, 2020 


\section{AUTHOR'S DECLARATION FOR ELECTRONIC SUBMISSION OF A}

\section{THESIS}

I hereby declare that I am the sole author of this thesis. This is a true copy of the thesis, including any required final revisions, as accepted by my examiners.

I authorize Ryerson University to lend this thesis to other institutions or individuals for the purpose of scholarly research.

I further authorize Ryerson University to reproduce this thesis by photocopying or by other means, in total or in part, at the request of other institutions or individuals for the purpose of scholarly research.

I understand that my thesis may be made electronically available to the public. 


\begin{abstract}
Simulation methods and software engineering principles for the analysis of cost-effective disease prevention, Arman Hamzehlou Kahrizi, Master of Science in Management (MScM), Ryerson University, 2020.
\end{abstract}

The Canadian healthcare system is among the most well-recognized healthcare systems in the world; however, it has been facing many challenges in several recent years.

In this paper, we plan to understand how Software Engineering and Software Reuse can help the Canadian Healthcare system become more efficient and effective in treating chronic illnesses and for this thesis primarily Type-2 Diabetes (T2D).

The investigators in this research, attempt to understand the current state of healthcare in Canada and then, with the help of Software Engineering and Software Reusability concepts, propose a simulation software package.

In the end, we used the developed software to simulate a randomized controlled trial (RCT) for testing the cost-effectiveness of two prevention programs of gym incentives and diabetes prevention program versus a control group not enrolled in any prevention program. 


\section{Acknowledgment}

I want to express my gratitude toward my supervisor Dr. Aziz Guergachi, who made this research possible through his continuous guidance and advice. During our weekly meetings, there was always something to learn and explore. When I started working with Dr. Guergachi, I thought I knew a lot, and it took me almost a year to realize that I do not know enough in this field. He has always notified me of possible conference opportunities and workshops which could advance my knowledge and put me in a higher position.

I am thankful to Dr. Guergachi for opening my eyes to realize the challenges I should prepare for if I want to pursue a Ph.D., and I believe this thesis has been a significant step in the right direction to prepare for the academic world. 


\section{Table of Contents}

AUTHOR'S DECLARATION FOR ELECTRONIC SUBMISSION OF A THESIS ................. ii

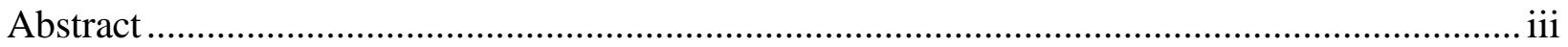

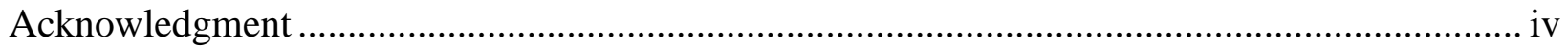

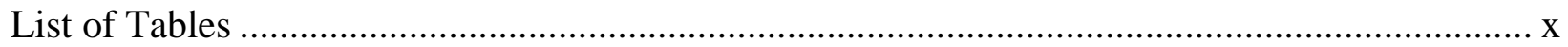

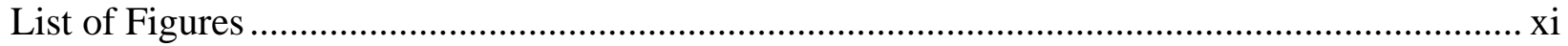

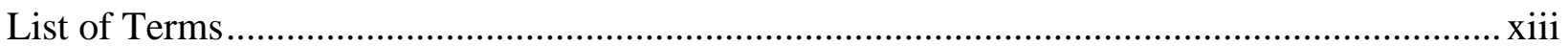

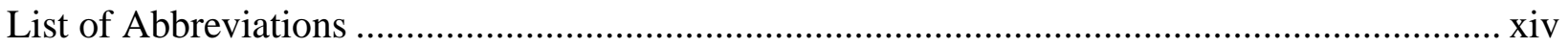

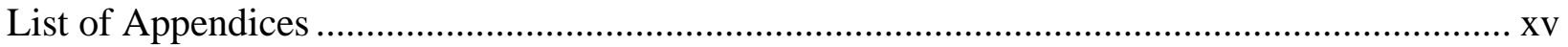

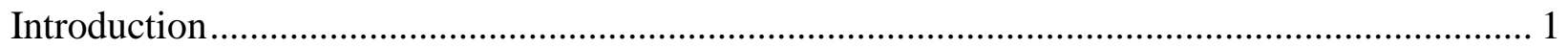

Trends in Canadian Healthcare System: .................................................................... 1

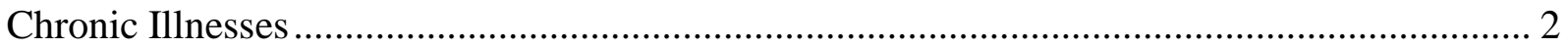

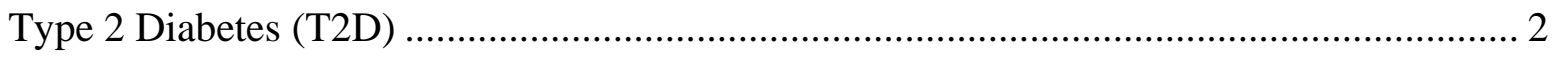

Software Engineering and Software Reuse in Healthcare Systems ..................................... 3

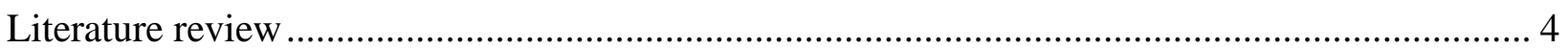

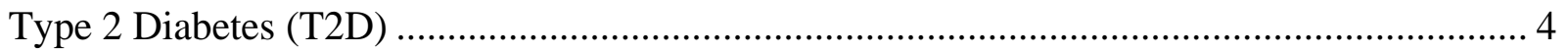

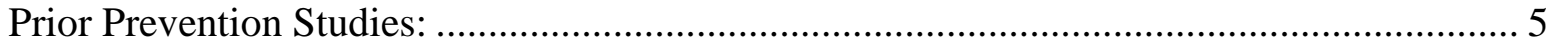

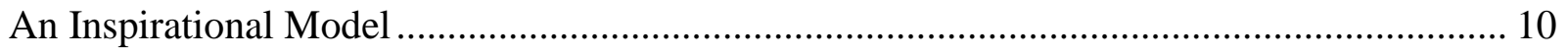

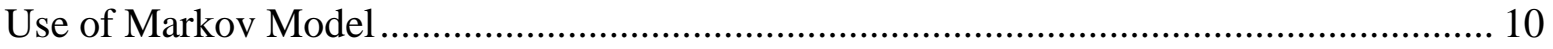


Variables of the Study.

Cost of Diabetes in Canada.

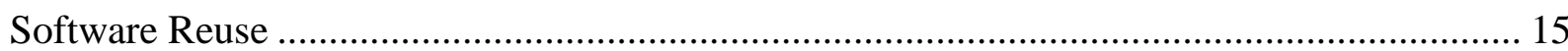

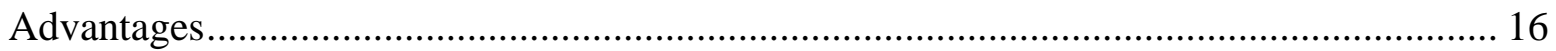

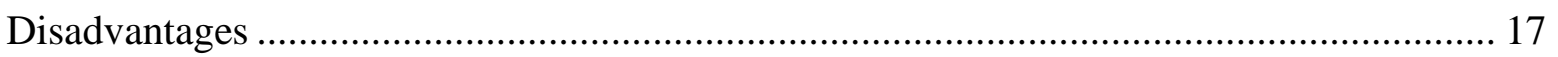

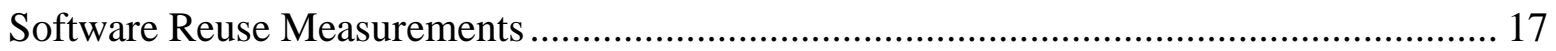

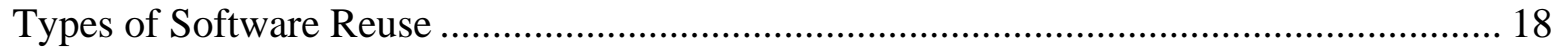

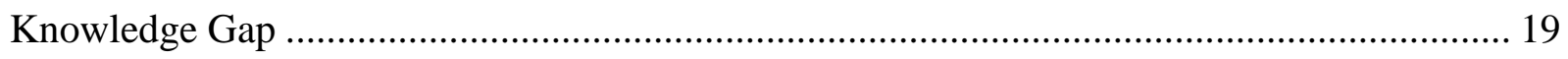

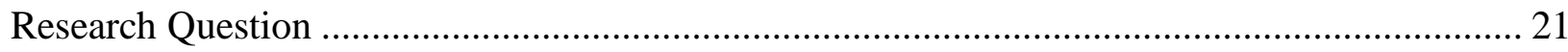

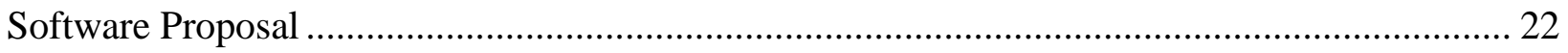

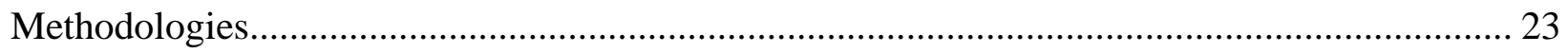

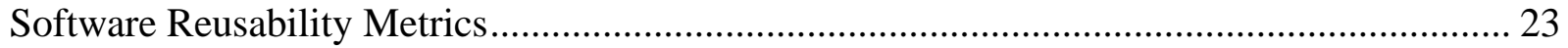

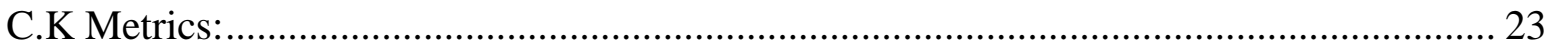

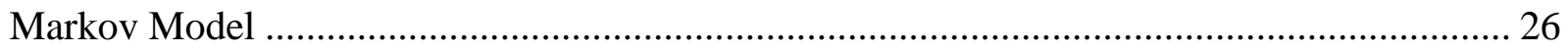

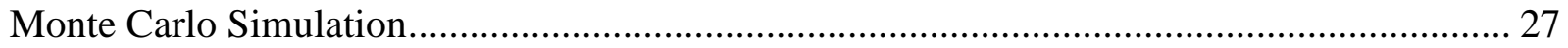

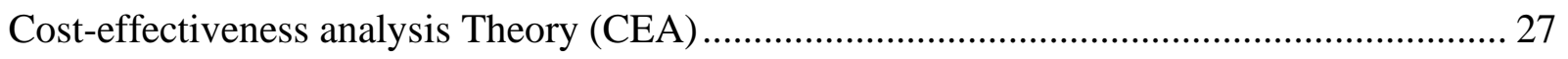

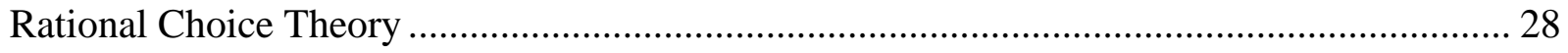

Development Tools and Design Patterns .................................................................. 29

Microsoft SQL Server Express ....................................................................... 29 
Microsoft Visual Studio 2019 Community Edition

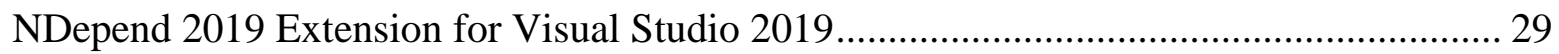

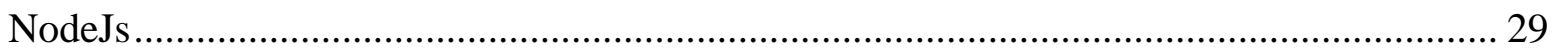

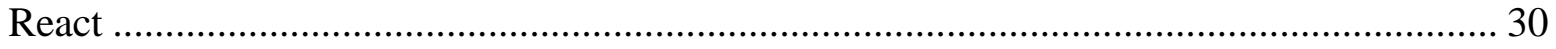

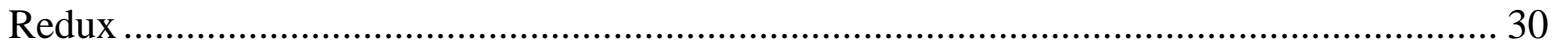

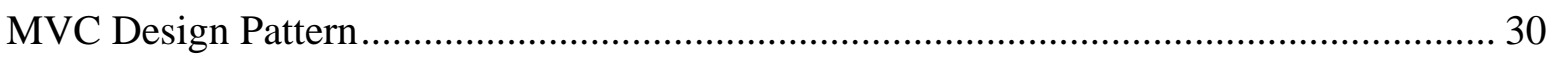

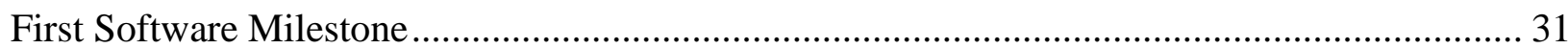

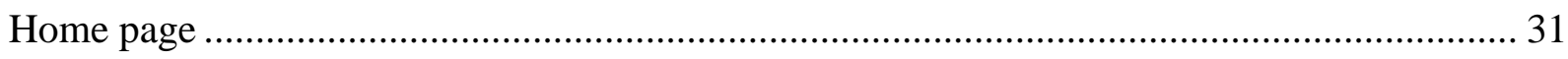

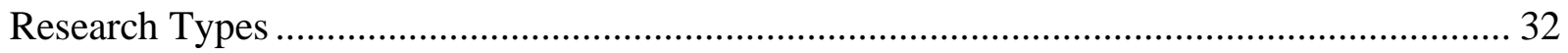

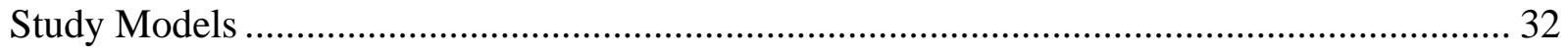

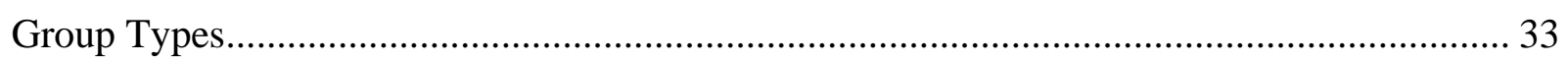

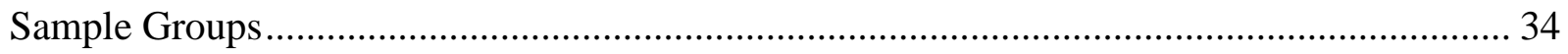

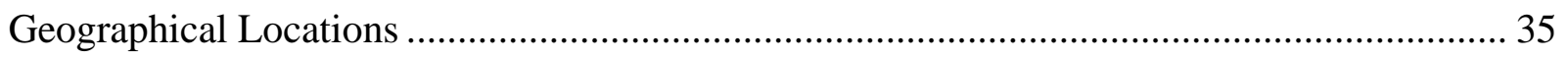

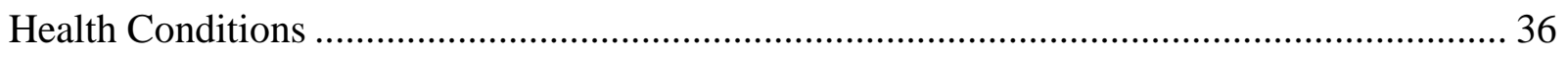

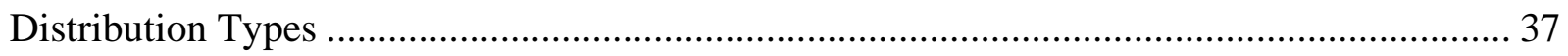

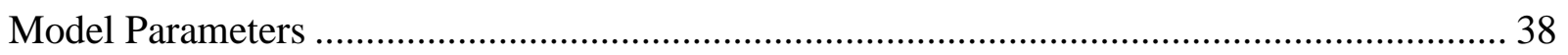

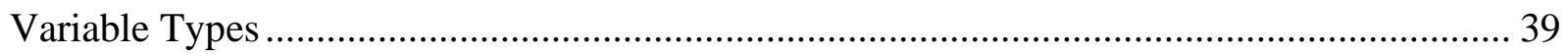

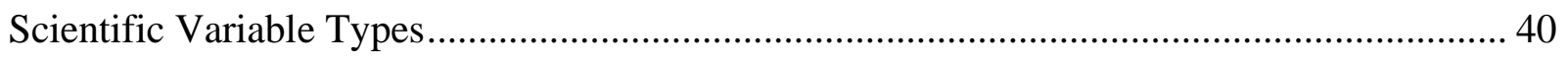

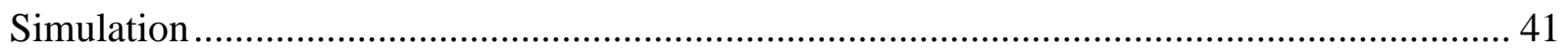


Simulation Dashboard.

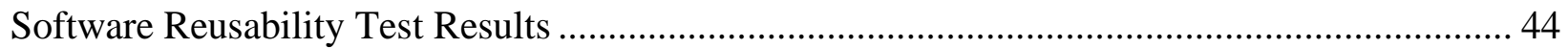

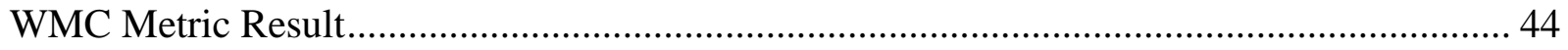

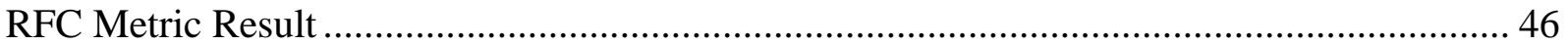

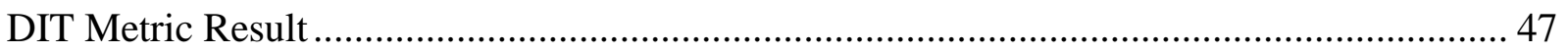

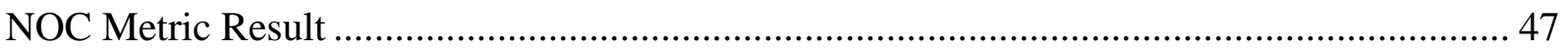

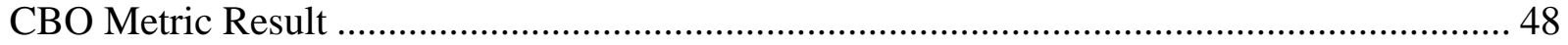

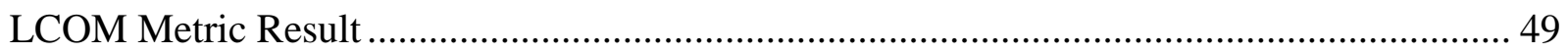

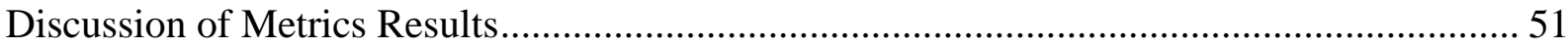

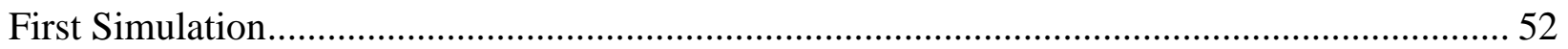

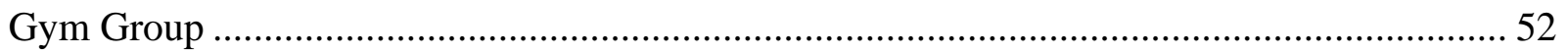

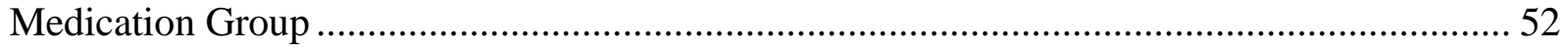

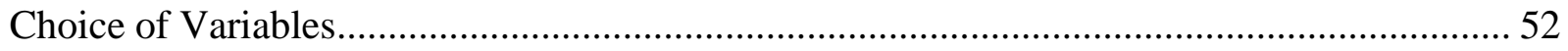

List of Variables Used in the model .......................................................................... 53

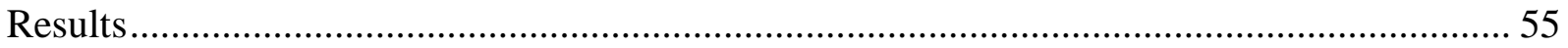

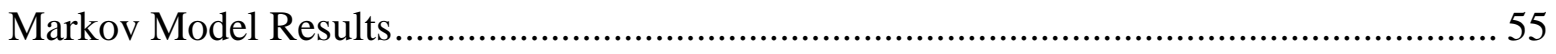

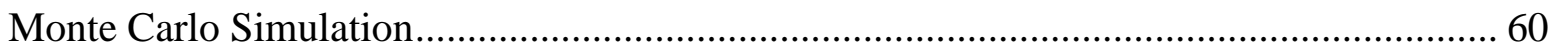

Discussion of The Simulation Results ......................................................................... 61

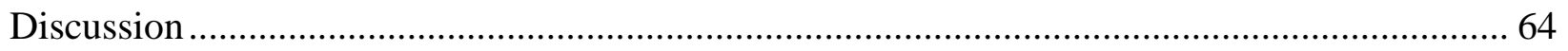




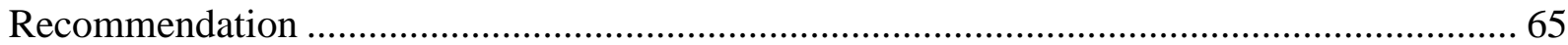

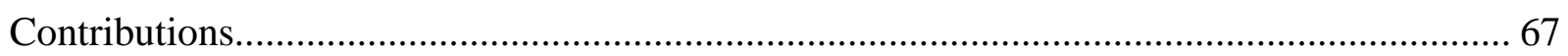

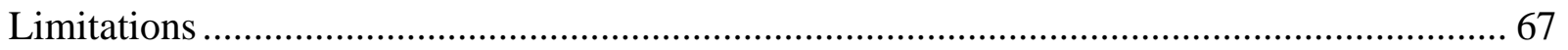

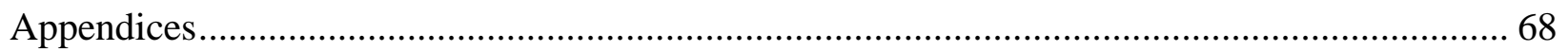

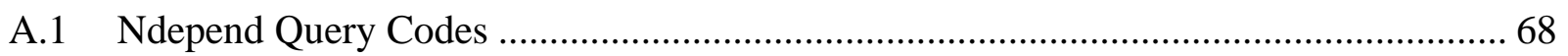

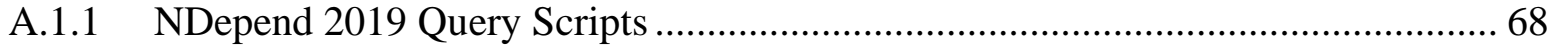

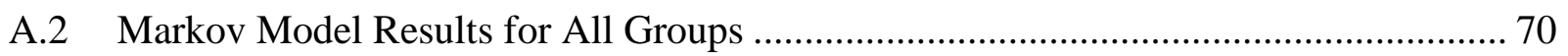

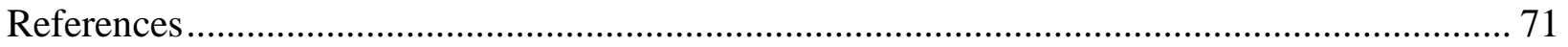




\section{List of Tables}

Table 1: Independent Variables Used in Markov Model to Examine the cost-effectiveness of

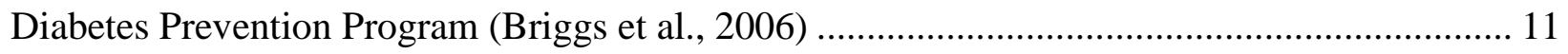

Table 2: Controlled Variables Used in Markov Model to Examine the cost-effectiveness of

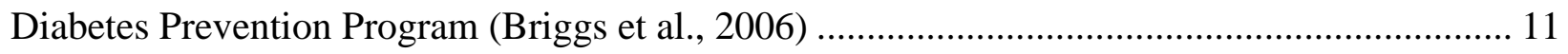

Table 3 Response Variables Used in Markov Model to Examine the cost-effectiveness of Diabetes

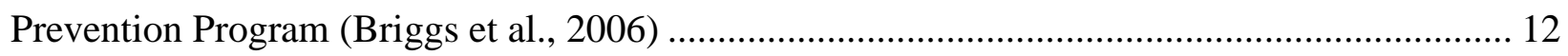

Table 4 Inflation Adjusted Costs associated with Type 2 Diabetes annually for a Canadian ...... 15

Table 5 Results of the Reusability Metrics Test ............................................................... 51

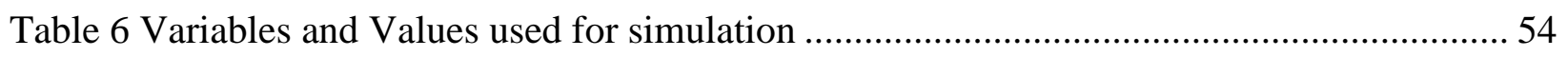

Table 7 Results of the 1,000 simulations through Monte Carlo Simulation.............................. 60

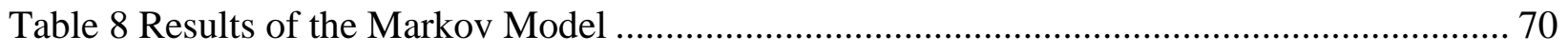




\section{List of Figures}

Figure 1 Simulation Software - Home Section ................................................................................. 31

Figure 2 Simulation Software - Research Types Section .............................................................. 32

Figure 3 Simulation Software - Study Models Section .............................................................. 33

Figure 4 Simulation Software - Group Types Section..................................................................... 34

Figure 5 Simulation Software - Sample Groups Section ......................................................... 35

Figure 6 Simulation Software - Geographical Locations Section ................................................ 36

Figure 7 Simulation Software - Health Conditions Section.......................................................... 37

Figure 8 Simulation Software - Distribution Types Section....................................................... 38

Figure 9 Simulation Software - Model Parameters Section.......................................................... 39

Figure 10 Simulation Software - Variable Types Section .......................................................... 40

Figure 11 Simulation Software - Scientific Variables Section ...................................................... 41

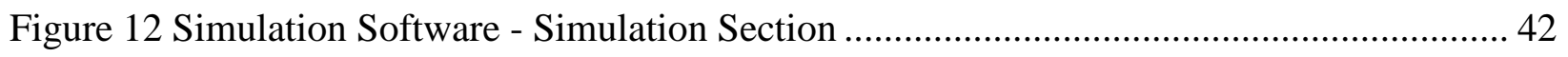

Figure 13 Simulation Software - Simulation Dashboard Section ................................................ 43

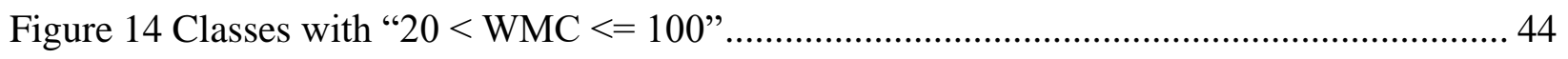

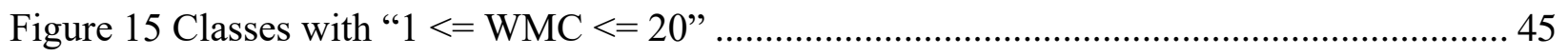

Figure 16 RFC Value for classes across the solution .................................................................. 46

Figure 17 DIT Value for classes across the solution ............................................................... 47

Figure 18 NOC Value for the HealthEconomics Solution.......................................................... 48 
Figure 19 CBO Value for classes across the solution

Figure 20 LCOM graph for the HealthEconomics Solution generated by NDepend 2019 (ZEN

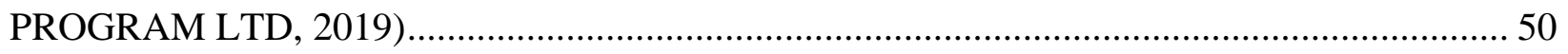

Figure 21 Overview of The Dashboard Values of The First Simulation .................................. 55

Figure 22 Plot of The Total Number of Individuals in an Asymptomatic Stage of the Disease .. 56

Figure 23 Plot of The Total Number of Individuals in a Progressive State of the Disease .......... 56

Figure 24 Plot of Total Quality-Adjusted Life-Years Across for the Three Participating Groups57

Figure 25 Plot of Average Annual Cost of Remaining in the Current State of The Disease for the

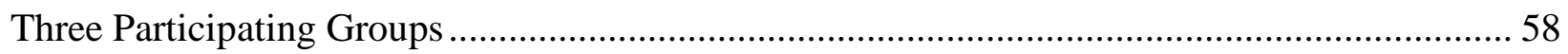

Figure 26 Plot of the Annual Total Costs of the Three Participating Groups........................... 59

Figure 27 Plot of The Accumulated Deaths per Group Over the Years .................................. 59 


\section{List of Terms}

\section{Term}

Quality-Adjusted
Life-Years

Quality-Adjusted Life Expectancy

Life Expectancy

Life-Years

Class
Short Explanation

Field

A year of life adjusted for its quality. One year in perfect health is equal to one QALY unit whereas the value of a year in ill health discounts the QALY unit (William C. Shiel, 2018).

Measures of the burden of disease. In other words, it measures the quantity and quality of years of life lived Healthcare (NCCID, 2015).

The number of years a person would be expected to live, starting from birth (Statistics Canada, 2009).

Healthcare

The additional years of life lived as a result of an intervention (European Patients' Academy, 2015).

A class is a set of objects sharing a common structure and a common behaviour manifested by the set of methods Computer within that class (Selvarani, Gopalakrishnan Nair, Science Ramachandran, \& Prasad, 2009). 


\section{List of Abbreviations}

\begin{tabular}{|c|c|c|}
\hline Abbreviation & Full Written Form & Context \\
\hline $\mathbf{A N N}$ & Artificial Neural Network & Computer Science \\
\hline AUSDRISK & Australian Type 2 Diabetes Risk & Healthcare \\
\hline CBO & Coupling between Object Classes & Computer Science \\
\hline CEA & Cost-Effectiveness Analysis & Economics \\
\hline DIT & Depth of Inheritance Tree & Computer Science \\
\hline GTA & Greater Toronto Area & Geography \\
\hline IDE & Integrated Development Environment & Computer Science \\
\hline LCOM & Lack of Cohesion of Methods & Computer Science \\
\hline LE & Life Expectancy & Healthcare \\
\hline LY & Life-Years & Healthcare \\
\hline MVC & Model-View-Controller & Computer Science \\
\hline MVVM & Model-View-ViewModel & Computer Science \\
\hline NOC & Number of Children & Computer Science \\
\hline OO & Object-Oriented & Computer Science \\
\hline QALE & Quality-Adjusted Life Expectancy & Healthcare \\
\hline QALY & Quality-Adjusted Life-Years & Healthcare \\
\hline RFC & Responses for a Class & Computer Science \\
\hline RCT & Randomized Controlled Trials & Medical Science \\
\hline SE & Software Engineering & Computer Science \\
\hline SPA & Single-Page Application & Computer Science \\
\hline T2D & Type 2 Diabetes & Healthcare \\
\hline WMC & Weighted Methods per Class & Computer Science \\
\hline
\end{tabular}




\section{List of Appendices}

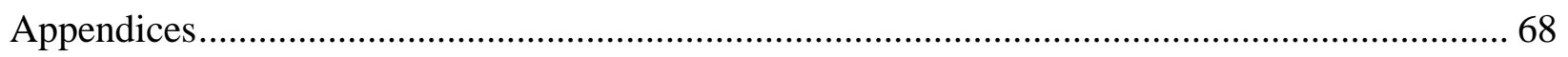

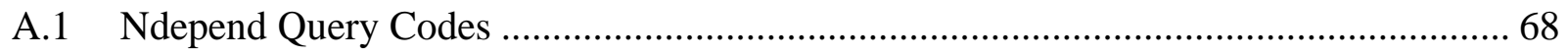

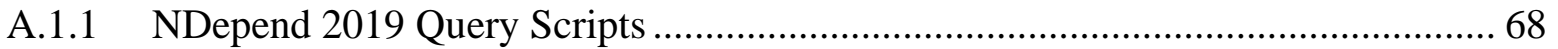

A.2 Markov Model Results for All Groups ........................................................... 70 


\section{Introduction}

\section{Trends in Canadian Healthcare System:}

In recent years, the provincial governments within Canada have increased their healthcare expenditure, and currently, they are reaching their expenditure limits, and this inclination has been observable since the past five years (Friday, 2018).

The population of Canada is expected to increase over the next 25 years to range from 40.1 million to 47.7 million by the year 2036 (Statistics Canada, 2011).

The percentage of senior Canadians has been increasing since 1960, growing from $8 \%$ during the 1960's to $14 \%$ in 2009. According to all population projection scenarios, seniors Canadians are expected to account for $23 \%$ to $25 \%$ of the Canadian population by the year 2036, and $24 \%$ to 28\% by the year 2061 (Statistics Canada, 2011).

While Canadians aged 65 and older form only $16 \%$ of Canada's population, they require approximately $46 \%$ of all public-sector health care budgets. Although seniors are a diverse group (Canadian Institute for Health Information, 2018).

In a report by the Canadian Institute for Health Information (2018), individual expenditure for senior Canadians increases with age. The average individual spending annually was CAD 6,607 for the age group of 65 to 69 , CAD 8,495 for the age group of 70 to 74, CAD 11,570 for the age group of 75 to 79 , and CAD 21,407 for the age group of 80 years old and older.

In 2016, approximately 63,459 Canadians sought non-emergency medical treatment outside Canada, of which 9,454 of them have been for general surgeries. This upsurge is considered an 
immense jump from the year 2014 with only 52,513 Canadians having sought non-emergency medical treatments from abroad. There has been a $20.84 \%$ increase in just two years (Esmail, 2017)

\section{Chronic Illnesses}

Annually, $67 \%$ of all deaths are a result of one of the four primary chronic diseases: cancer, diabetes, cardiovascular and chronic respiratory diseases. Comparing with the given figure, more Canadian adults of working age between 34 to 64 years old are living with chronic conditions. Four out of five Canadians are at risk of chronic illness, while three out of five Canadians of twenty years of age or older already have a chronic disease (Public Health Agency of Canada, 2013).

The direct cost of chronic diseases forms 58\% of the annual healthcare costs in Canada (Chronic Disease Prevention Alliance of Canada, 2017).

\section{Type 2 Diabetes (T2D)}

Amongst the four primary chronic diseases, since the year 2004 until 2008, a total of 120,050 Type-2 Diabetes (T2D) related deaths were documented in Canada. This number accounts for $10.6 \%$ of all documented deaths in Canada during that period. Remarkably, T2D was more than twice as likely to be an influential factor rather than being the primary cause of the deaths (Park \& Peters, 2014). 


\section{Software Engineering and Software Reuse in Healthcare Systems}

In healthcare settings, traditional software engineering, in most scenarios, has primarily focused on machinery rather than people, as it models the communication between people and machinery as a function of the machine. This concept is practical only if the software engineer has a profound understanding of the system functions. However, in healthcare software engineering where software and process structures are more complex, building a software system that acts as the central entity to control the system will potentially fail. Healthcare systems and software applications are successful only if they seamlessly support medical experts and integrate patients in all of the processes (Solanas, Weber, Bener, van der Linden, \& Capilla, 2017).

In recent years, many communities and venues in the healthcare system have appeared as a result of software engineering (SE). The popularity of this topic has been negativity affected by dangerous failures of software-intensive networks which were designed and developed to address the challenges in the healthcare field (Weber-Jahnke, Price, \& Williams, 2013).

The concept of software reuse can help make information technology products more efficient for clients and cheaper to develop. Software reuse is not limited to only the code aspects; it can be the reuse of existing documents, coding styles, components, models, patterns and knowledge (Macedo, Baranauskas, \& Bulcão-Neto, 2018).

As discussed earlier, the Canadian population is progressively becoming older, and costs associated with healthcare will rise. 


\section{Literature review}

This review will inspect the current knowledge of T2D, the prevention and treatment strategies for this disease and the economics and cost-effectiveness of the prevention programs. In this section review, we will also explore the literature of Software Engineering and Software Reuse. We will then use the reviewed research to identify an area in which Software Engineering and Software Reuse can help improve the state of healthcare in Canada in dealing with Type 2 Diabetes.

\section{Type 2 Diabetes (T2D)}

T2D is a chronic metabolic illness which leads to higher than average blood glucose (sugar) and is the most common type of diabetes. In type 2 diabetic individuals, the body is not able to consume the insulin properly (insulin resistance), and so to compensate for the absence of sugar due to body's inability to use it, the body starts to release more sugar into the bloodstream to respond to the shortage of sugar it is sensing. If untreated T2D can become a fully developed disease (Ministry of Health and Long-Term Care - Government of Ontario, 2012).

There is increasing evidence that the number of T2D incidences has significantly grown in recent years. This increase is affected by several factors such as obesity, sedentary lifestyle, and the fact that the population of Canada is getting older (Ministry of Health and Long-Term Care Government of Ontario, 2012).

Diabetes can lead to countless severe health conditions and cause severe damage to body cells and organs. Diabetes may cause eye damage resulting in blindness. Type 2 Diabetes can also cause Kidney damage resulting in kidneys not being able to eliminate the waste, additional salt, and water from the body, and in such circumstances, the patient will require dialysis as it can be lifethreatening health complication. Diabetes can also impair the heart tissues and muscles, which 
leads to strokes and heart attack. There are many occurrences in which diabetes has led to infection and nerve damage beyond the point of recovery, and, in that case, amputation surgery is necessary for the patient to survive (Ministry of Health and Long-Term Care - Government of Ontario, 2012).

With the growing number of diabetes incidents, the cost of treatment also increases, and in several countries and regions around the world, it has become a priority to design a model which will help healthcare systems and clinics to better diagnose those individuals at risk of developing T2D. Most arguments against the prevention are that these prevention practices are not cost-effective.

\section{Prior Prevention Studies:}

A study was conducted in the Australian healthcare setting to compare the diabetes prevention outcomes and costs of screening strategies for type 2 diabetes prevention programs which included an oral glucose tolerance test. The study used the Australian type 2 diabetes risk assessment (AUSDRISK) tool and consisted of 4,864 participants from the "Australian Diabetes, Obesity, and Lifestyle" study 40 years old or older. The researchers determined that a blood test assessment is a vital step for registering participants in a diabetes prevention program. There will be unqualified patients who still proceed to diabetes (C. M. Y. Lee et al., 2018).

The study above proposes a cost-effective step to recognize individuals at risk of T2D. Though, it fails to address those cases that individuals were not eligible for the prevention program and continued to develop diabetes. From the social-value viewpoint, we need to implement a more competent system or algorithm that could reduce the possibilities of such oversights.

A study by Hoogendoorn, Rutten, Hart, de Wolf, \& Vos (2019) for two Dutch primary healthcare centers measured the result of a supervised walking program in highly motivated individuals with type 2 diabetes or at risk of developing it. The study concluded that once a week, a rigorous and 
supervised walking program, has beneficial results for the body, blood pressure, as well as the well-being of the individuals.

Anderson (2012) argues that lifestyle interventions in the United States for individuals of 65 years old and older are very cost-effective and inexpensive for a healthcare insurance payer. He similarly recommends that it is possible that nutrition therapy can be even more cost-effective, and that it brings monetary benefits to insurance companies by implementing such practices in healthcare settings. This practice is useful, and as we discussed earlier in the introduction of this proposal, medical expenditures increase with age for senior individuals 65 years old or older. The study expects that lifestyle interventions become increasingly cost-effective with the increment of age.

Another study revealed that intensive lifestyle modification for patients with impaired glucose tolerance is cost-saving and very cost-effective both short-run and long-run through a one-on-one counselling and consulting setting. The study finally argues that if clinicians can reduce the costs for lifestyle modification, then the intervention can be more cost-effective and can result in health improvement and efficiency of usage in healthcare resources (R. Li, Zhang, Barker, Chowdhury, \& Zhang, 2010).

It is not possible to decrease the costs of lifestyle interventions across all programs since it highly varies on the type of intervention and by which healthcare setting it is being practiced. In such situations, clinicians and specialists will have to prescribe what is essential to get the best result for the intervention and not incur any additional costs.

Neumann et al. (2017) investigated the Type 2 Diabetes in a Swedish healthcare setting, and authors concluded that the prevention or the delaying of the inception of type 2 diabetes is costeffective, and a small investment in lifestyle intervention can be very cost-effective. In this study 
they used a Markov Model $^{1}$ with one treatment group receiving a lifestyle intervention and a control group receiving no lifestyle modification. A Monte Carlo simulation was later used to validate the result of the Markov model for different age groups and genders.

Among various types of interventions, Drug interventions are also a popular strategy. For example, "Atorvastatin" is a medication which is often prescribed to help lower cholesterol levels and avoid cardiovascular diseases (WebMD, 2019).

An investigation for Chinese healthcare settings argues that because diabetic individuals are likely to develop cardiovascular diseases, it is vital to lessen the risks of cardiovascular diseases in those individuals. The study determined that assumed a cost-effectiveness minimum of CAD 27,351 per QALY $^{2}$ gained, Statin ${ }^{3}$ treatment with Atorvastatin ${ }^{4}$ is $80 \%$ likely to be cost-effective for newly diagnosed individuals (T. Li, Wan, Ma, \& Wu, 2018).

Herman (2015) investigated Type 2 Diabetes prevention cost-effectiveness through a simulated lifetime as well as a 10-year trial economic analysis. The author determined that lifestyle and metformin (a medicine to manage type 2 diabetes) interventions were cost-effective compared to no intervention at all. The study concluded that prevention programs for diabetes in high-risk individuals would bring substantial health benefits, have good value for money, and promote social value and well-being.

\footnotetext{
${ }^{1}$ Markov model is a stochastic model that uses probabilities specified by researchers to predict the next state of a set of data only by studying one last state of those data (Kaelbling, Littman, \& Cassandra, 1998).

${ }^{2}$ Quality adjusted life year (QALY) is a year of life that is adjusted for its quality. This means that one year in perfect health is considered equal to 1.0 QALY while the value of a year in ill health is discounted (William C. Shiel, 2018).

${ }^{3}$ A medication to help lower cholesterol levels in the blood (WebMD, 2019).

${ }^{4}$ A medication to help lower cholesterol levels in the blood (WebMD, 2019).
} 
During a study by Palmer \& Tucker (2012) in Australia for high-risk patients treated with metformin or intensive lifestyle intervention, it was determined that from a 3rd-party payer standpoint, the metformin and lifestyle intervention approaches for T2D individuals is good value for money, and may lead to long-term cost-saving for the intensive lifestyle interventions.

Sussman, Kent, Nelson, \& Hayward (2015) carried out a clinical investigation to determine whether there were individuals in the Diabetes Prevention Program (a clinical trial in the United States) who were likely benefit from drug or a lifestyle intervention program compared to the rest of the participants. The study determined that even though the Diabetes Prevention Program proposed that both lifestyle and drug intervention can prevent progression of diabetes, individuals who are likely to develop T2D at a younger age, benefited more from the lifestyle intervention and the prevention for these individuals is more valuable.

In a study by Herman (2017), the author concluded that lifestyle interventions for Type 2 Diabetes are useful for nearly all groups of diabetic individuals, and that it is associated with enhanced quality of life as it has fewer side-effects compared to medication approach, and that it is a costeffective practice. The study additionally confirms that metformin ${ }^{5}$ is similarly beneficial, safe and cost-effective, particularly in younger and more overweight individuals who are pre-diabetic as well as women with past gestational diabetes.

This study is highlighting mainly on interventions aiming at individuals with the highest risk of diabetes, whereas individuals with lower risk cannot enroll in the intervention program. The drawback of such a tactic is that it will leave many individuals with the potential of disease progression out of the prevention program.

\footnotetext{
${ }^{5}$ A medicine to manage type 2 diabetes
} 
Up until now, the literature points to the exclusion of a cluster of patients to make a prevention program economical, while some studies proposed a rudimentary clinical follow-up with diabetic individuals with the assumption of patient adherence to the given tasks and practices. Finally, only a few papers and reports point to existing knowledge for the Canadian healthcare setting. 


\section{An Inspirational Model}

Briggs, Claxton, \& Sculpher (2006) performed a cost-effectiveness analysis of type 2 diabetes in which they accounted for a set of controlled and fixed variables such as probability ratios and costs of the symptom or symptomatic disease annually as well as independent variables such as the natural risk of death based on age.

\section{Use of Markov Model}

Briggs, Claxton, \& Sculpher (2006) used those variables to develop a Markov Model and Monte Carlo Simulation that helped them examine the cost-effectiveness of a prevention program with a length of 45 (cycles) years, enrolling 1,000 diabetic individuals over the age of 55 in the United Kingdom.

\section{Variables of the Study}

Table 1 is a preview of all the variables used in the development of their model. These variables all have ranged from Min to Max, so the Monte Carlo simulation can use those ranges to generate a stochastic value and perform the simulation based on that.

\begin{tabular}{|c|c|c|c|c|}
\hline Name & Mean & Min & Max & Variable description \\
\hline cAsymp & 500 & 250 & 750 & $\begin{array}{l}\text { Cost of one cycle in the asymptomatic disease } \\
\text { state }\end{array}$ \\
\hline cDeath & 1000 & 500 & 1500 & $\begin{array}{l}\text { The cost associated with the transition to the dead } \\
\text { state }\end{array}$ \\
\hline cDrug & 1000 & 800 & 1200 & Cost of the drug for one cycle \\
\hline tpDcm & 0.15 & 0.10 & 0.20 & $\begin{array}{l}\text { Probability of dying from the disease in a single } \\
\text { cycle }\end{array}$ \\
\hline cProg & 3000 & 2000 & 4000 & Cost of one cycle in the progressive disease state \\
\hline effect & $50 \%$ & $40 \%$ & $60 \%$ & $\begin{array}{l}\text { Effectiveness of drug in terms of reducing disease } \\
\text { progression }\end{array}$ \\
\hline tpProg & 0.010 & 0.005 & 0.015 & $\begin{array}{l}\text { Coefficient of increase for probability of entering } \\
\text { the progressive disease state }\end{array}$ \\
\hline uAsymp & 0.95 & 0.90 & 1.00 & $\begin{array}{l}\text { Quality of life weight for one cycle in the } \\
\text { asymptomatic disease state }\end{array}$ \\
\hline
\end{tabular}




\begin{tabular}{ll|l|l|l|} 
uProg & 0.75 & 0.6 & 0.9 & $\begin{array}{l}\text { Quality of life weight for one cycle in the } \\
\text { progressive disease state }\end{array}$
\end{tabular}

Table 1: Independent Variables Used in Markov Model to Examine the cost-effectiveness of Diabetes Prevention Program (Briggs et al., 2006)

Table 2 demonstrates a list of controlled variables Briggs et al. (2006) used in the development of their Markov Model.

\begin{tabular}{|c|c|c|}
\hline cycle & Value & Length in years of one cycle \\
\hline ini_age & 55 & The initial age at which patients are deemed to start the model \\
\hline cDR & $6 \%$ & The discount rate ${ }^{6}$ for costs \\
\hline oDR & $6 \%$ & The discount rate for outcomes \\
\hline nD35 & 0.0017 & Natural death risk for over 35's \\
\hline nD45 & 0.0044 & Natural death risk for over 45 's \\
\hline nD55 & 0.0138 & Natural death risk for over 55 's \\
\hline nD65 & 0.0379 & Natural death risk for over 65 's \\
\hline nD75 & 0.0912 & Natural death risk for over 75 's \\
\hline nD85 & 0.1958 & Natural death risk for over 85 's \\
\hline
\end{tabular}

Table 2: Controlled Variables Used in Markov Model to Examine the cost-effectiveness of Diabetes Prevention Program (Briggs et al., 2006)

\footnotetext{
${ }^{6}$ Discount Rate: In economic evaluations we need to adjust the value of costs and benefits for the time at which they occur, this technique is also known as discounting. Effects of discounting on final outcomes may be substantial (Attema, Brouwer, \& Claxton, 2018).
} 
In Table 3, we have listed a list of all response variables Briggs et al. (2006) have used in their study.

\begin{tabular}{|c|c|c|}
\hline Name & Description & Formula \\
\hline Cycle & The current cycle/year & N/A \\
\hline nDeath & $\begin{array}{l}\text { Natural risk of death for individuals at } \\
\text { their current age }\end{array}$ & $\begin{array}{l}\text { This variable is computed manually using multiple } \\
\text { conditional statements. }\end{array}$ \\
\hline Asymp & $\begin{array}{l}\text { The number of individuals being in } \\
\text { the asymptomatic stage of the disease }\end{array}$ & Asymp $_{\text {Previous }}-$ Death - Prog \\
\hline Prog & $\begin{array}{l}\text { The number of individuals being in } \\
\text { the progressive state of the disease }\end{array}$ & $\begin{array}{l}\operatorname{Prog}_{\text {Previous }} \times\left(1-\text { tpDcm }- \text { nDeath }_{\text {Previous }}\right)+ \\
\text { Asymp } \\
\text { Previous } \\
\times \text { tpProg } \times \text { Cycle }\end{array}$ \\
\hline Death & $\begin{array}{l}\text { The total number of deaths as of the } \\
\text { current cycle }\end{array}$ & $\begin{array}{l}\text { Previous }_{\text {Death }}+\text { Prog }_{\text {Previous }} \times \text { tpDcm }+ \\
(\text { Asymp } \\
\text { Previous } \\
\left.+ \text { Prog }_{\text {Previous }}\right) \times \text { Cycle }_{\text {Previous }}\end{array}$ \\
\hline $\mathbf{L E}$ & $\begin{array}{l}\text { Total number of years all individuals } \\
\text { in the program are expected to live }\end{array}$ & Asymp + Prog \\
\hline QALE & $\begin{array}{l}\text { Total units of quality of life for the } \\
\text { additional life-years gained due to } \\
\text { intervention }\end{array}$ & Asymp $\times$ uAsymp + Prog $\times$ uProg \\
\hline LY & $\begin{array}{l}\text { Total Additional number of life-years } \\
\text { individuals live as a result of the } \\
\text { intervention }\end{array}$ & $\frac{\text { Asymp + Prog }}{(1+o D R)^{\text {Cycle }}}$ \\
\hline QALY & $\begin{array}{l}\text { Total units of disease burden, } \\
\text { including both the quality and the } \\
\text { quantity of life, lived across all } \\
\text { individuals }\end{array}$ & $\frac{\text { Asymp } \times \text { uAsymp } \times \text { Prog } \times u \text { Prog }}{(1+o D R)^{C y c l e}}$ \\
\hline StateCost & $\begin{array}{l}\text { Cost of staying in the current state of } \\
\text { the disease for all individuals }\end{array}$ & $\frac{\text { Asymp } \times \text { cAsym } p+\text { Prog } \times \text { cProg }}{(1+c D R)^{C y c l e}}$ \\
\hline TransCost & $\begin{array}{l}\text { Cost of transitioning to another state } \\
\text { of the disease for all individuals. }\end{array}$ & $\frac{\text { PreviousProg } \times \text { tpDcm } \times \text { cDeath }}{(1+\mathrm{cDR})^{\text {Cycle }}}$ \\
\hline TotalCost & $\begin{array}{l}\text { The total cost of staying in the current } \\
\text { state of the disease plus the cost of } \\
\text { transitioning to another state of the } \\
\text { disease }\end{array}$ & StateCost + TransCost \\
\hline
\end{tabular}

Table 3 Response Variables Used in Markov Model to Examine the cost-effectiveness of Diabetes Prevention Program (Briggs et al., 2006) 
Briggs et al. (2006) have confirmed the robustness of the model output through a Monte Carlo Simulation. Monte Carlo Simulation uses the Max and Min values of each independent variable to generate a stochastic value, which then can be processed by a Markov Model in each cycle of simulation.

In this thesis, we plan to use the logic defined in the above paper and model to create a simulation package to use in the software we have specially developed which allows to dynamically run and analyze as many scenarios as possible.

There are certain variables which remain the same for our paper, while several other variables must be updated to match the Canadian settings. Among the variables which stay the same are the discount rates and natural death risk base on the age group of individuals.

Variables such as the cost of the drug or being in an asymptomatic/progressive state of the diabetes type 2 disease for one year and costs associated with death of a diabetic type 2 individual need to be updated and adjusted to Canadian prices and healthcare settings.

\section{Cost of Diabetes in Canada}

\section{A.1.1.1 Drug Cost}

According to a report by Canadian Agency for Drugs and Technologies in Health (2018), the price of a drug called Metformin, that individuals in an asymptomatic state need to take in order to manage their diabetes type 2 symptoms is CAD 0.29 per day for a 2,000mg dosage which is the average required dose for a diabetic individual. Please note that in this report, the average weight of individuals was 87 kilograms. 
The above information allows us to compute the annual expenses associated with metformin each year for individuals not in a progressive state of the disease. The annual cost of the medication is as follow:

CAD $0.29 \times$ (number of days a year) $365=$ CAD 105.85 per year

\section{A.1.1.2 Cost of the Disease in Asymptomatic State}

Type 2 Diabetes can be either in an asymptomatic state or progressive state. According to Bilandzic \& Rosella (2017), we expect the costs of being in an asymptomatic state on average to be CAD 1,240 per year.

\section{A.1.1.3 Cost of the Disease in Acute/Progressive State}

Nevertheless, the costs associated with being in a progressive state of diabetes is much higher. According to an official report released by the Canadian Institute for Health Information (2007) on the average cost of acute/progressive diabetes type 2 for a Canadian is CAD 3,661 annually. After inflation adjusting this amount, it becomes a whopping CAD 4,478.19, which is more than three times more expensive compared to an asymptomatic stage of the disease.

\section{A.1.1.4 Cost of Death}

A recent study by Tanuseputro et al. (2015) argues that for each individual the average cost of the health care in the last year of life is CAD 53,661 and this number jumps to reach a CAD 14,000 in the final month of their life.

\section{A.1.1.5 The Inflation Adjusted Costs}

Using the online inflation rate calculator by the Bank of Canada (2019), we can adjust all the above values for the annual inflation rate. 


\begin{tabular}{|c|c|c|c|c|}
\hline Description & $\begin{array}{l}\text { Original } \\
\text { Cost }\end{array}$ & $\begin{array}{l}\text { Year } \\
\text { Obtained }\end{array}$ & $\begin{array}{l}\text { Inflation Rate Acquired from } \\
\text { the Bank of Canada (2019- } \\
\text { 08-27) }\end{array}$ & $\begin{array}{l}\text { Inflation } \\
\text { Adjusted } \\
\text { Cost }\end{array}$ \\
\hline $\begin{array}{l}\text { Cost of Metformin Drug for one } \\
\text { year }\end{array}$ & $\begin{array}{l}\text { CAD } \\
105.85\end{array}$ & 2018 & $\% 2.01$ & CAD 107.98 \\
\hline $\begin{array}{l}\text { Cost of being in the Progressive } \\
\text { State of T2D for one year }\end{array}$ & $\begin{array}{l}\text { CAD } \\
3,661\end{array}$ & 2007 & $\% 22.32$ & CAD 4,478.19 \\
\hline $\begin{array}{l}\text { Cost of being in the } \\
\text { Asymptomatic State of } \mathrm{T}^{2} \mathrm{D}^{7} \text { for } \\
\text { one year }\end{array}$ & $\begin{array}{l}\text { CAD } \\
1,240\end{array}$ & 2017 & $\% 5.06$ & CAD $1,302.76$ \\
\hline $\begin{array}{l}\text { Average Costs } 1 \text { Year Before } \\
\text { Death }\end{array}$ & $\begin{array}{l}\text { CAD } \\
53,661\end{array}$ & 2015 & $\% 7.62$ & CAD 57,749.86 \\
\hline
\end{tabular}

Table 4 Inflation Adjusted Costs associated with Type 2 Diabetes annually for a Canadian

\section{Software Reuse}

Software reuse is any use of previously developed software's life cycle such as product line requirements, functions, architecture, design patterns and codes to develop new software. Software developers should plan for reuse from the conception and initiation phases of software development (RADU, 2018).

Software reuse is a systematic practice of developing software from a set of building blocks so that similarities in requirements and architecture between software applications can be exploited to accomplish considerable benefits in productivity, quality and business performance (Morisio, Ezran, \& Tully, 2002).

\footnotetext{
${ }^{7}$ Type 2 diabetes
} 
Software reuse must not be confused with Software Reusability. Reusing any existing or accessibly available software components to save time, computation, financial and human resources are called software reusability (Padhy, Singh, \& Satapathy, 2018).

To avoid system abandonment or code $\operatorname{rot}^{8}$, Software developers and engineers need to develop software systems with extensibility and reusability in mind. We define extensibility as the ability of a software system to be extended with new functionality at minimal or no effects on its internal structure. Extensibility ultimately promotes reusability as they have many features in common with each other (Johansson, Löfgren, \& Olsson, 2009).

\section{Advantages}

Software reuse promotes dependability and effective use of specialist and creates standard compliance. In software reuse, we can implement more technology and tools on the same product domain (Huzumi, Mao, Kasi, \& Zhe, 2008).

Software Reuse allows the development of software frameworks as an abstraction of functionalities to build and deploy applications. Software frameworks are reusable designs of all or part of a software system. We describe Software framework as a set of codes, libraries, tools, APIs, and primarily abstract classes and the way these classes communicate with one another. Consequently, the key objective of a software framework is to allow the production of new software more efficiently through reuse (Macedo et al., 2018).

\footnotetext{
${ }^{8}$ Code Rot happens when software system ultimately becomes abandoned as the system is too hard to maintain and extend (Johansson et al., 2009).
} 


\section{Disadvantages}

Padhy et al. (2018) argue that Software ageing not only affects software reusability but also is a symptom of extreme reuse in the software environment, and it happens when there is excess reusability. There is a threshold value, which is one of the measurements of the reusability estimation level and exceeding that value will cause the software system to crash or fail. There are two types of software ageing:

\section{A.1.1.6 Lack of Movement}

Lack of movement happens when product's owners fail to modify it to meet the changing needs (Padhy et al., 2018).

\section{A.1.1.7 Ignorant Surgery}

In this type of software ageing, some changes are made to the system, introducing software faults, also known as software ageing. These faults could be component, OS (operating system) or application failure. In many cases, software ageing occurs as a result of excessive reuse, which is also known as a software fault. Failure will result in flawed services such as stopping, system crashes or incorrect results (Padhy et al., 2018).

\section{Software Reuse Measurements}

Some techniques can help categorize the reusability factor and help the choice of parameters and metrics related to software reusability. These techniques are evolutionary computing based ANNs for software reusability prediction, support vector machines, neural networks, genetic algorithms, fuzzy logic (Padhy et al., 2018). 


\section{Types of Software Reuse}

Depending on the type of components we are reusing, the type of reuse is different as well. We can categorize components into a Black box, White box and Glass box components (Mijač \& Stapic, 2015).

\section{A.1.1.8 Black box Components and Black box Reuse}

In Black box reuse, the components are reused without any changes typically because the component is a Black box component (RADU, 2018).

The external user of a Black box component can only see the interface of the component, while the implementation details of the component and its interfaces remain hidden (Mijač \& Stapic, 2015).

\section{A.1.1.9 White box Components and White box Reuse}

In White box reuse, the components must be modified based on the new requirements. The components to be reused could be libraries, software specifications, software design, interfaces, prototypes, planning, documentation, frameworks, test cases or templates. Some components are

also interrelated. For instance, the reuse of source components indirectly involves the reuse of analysis and design stages (RADU, 2018).

White-box components allow an external user to view the internal assembly of the component, with the difference that the white box component allows users to modify the source code (Mijač \& Stapic, 2015). 


\section{A.1.1.10 Glass-box Components and Glass-Box Reuse}

Very similar to Whitebox reuse, in Glass-box reuse, software developers reuse Glass-Box components which cannot be modified; however, the user can see the internal structure of the component to develop software applications (Mijač \& Stapic, 2015).

\section{Knowledge Gap}

The prevention programs can have multiple combinations of strategies and practices to achieve the desired objective by identifying and connecting with individuals at risk of T2D. This task will require human resources such as doctors, nurses, and facilitators, and there is a threshold which we must consider if we plan to keep the prevention more cost-effective compared to the treatment plan.

The implementation of a T2D prevention program in a real-world scenario is linked to high costs and could prevent only a few cases of diabetes, Therefore, in a cost-effectiveness analysis, we must also consider costs such as staff training, intervention participation and adherence (Icks et al., 2007).

A clinical trial was performed in the United States to understand the threshold at which lifestyle interventions for people aged 65 years and older become cost-effective (Anderson, 2012). It concluded that in a perfect case, for a 3-year prevention program to be cost-effective 212,225 cases of diabetes would need to be prevented and for a 10-year program to be cost-effective, up to 452,303 cases would need to be prevented. The study determined that the program is likely to have saved costs and increased health among women in two areas, but in the other three study groups, the changes in costs and QALYs (quality-adjusted life-years) were more unfavorable compared to the control group. 
Schwarz et al. (2008) argued that the development of effective screening and core intervention plans for the prevention of the T2D would significantly improve the ability of healthcare experts to swiftly respond to the drastic increase of $\mathrm{T} 2 \mathrm{D}$ and its burden to the healthcare system.

For a healthcare prevention plan to become cost-effective, there must be a behavioural change strategy, and the absence of an intensive provisioned individualized delivery will only resemble the control group interventions used by the Randomized controlled trials, and it cannot be valid (Baker, Simpson, Lloyd, Bauman, \& Singh, 2011).

Passey et al. (2012) suggested that prevention of diabetes with metformin or lifestyle interventions will significantly benefit the labour force and increases incomes for individuals as these individuals will remain healthy for longer and can continue with their daily tasks.

The first challenge is that most of the papers in the field of healthcare and diabetes have not targeted Canada for their study, which by itself is a knowledge gap that we can address. The number of studies conducted in Canadian health system settings is not significant.

Currently and based on the literature reviewed in the earlier part of this thesis, the translation of the outcomes from international studies into real-world within Canadian settings can be very challenging. 


\section{Research Question}

Throughout this investigation, we have documented a knowledge gap. We realize that it is naïve to claim that we can fill this knowledge gap on our own through this paper. Nevertheless, we recognize the opportunity to help contribute to filling this gap using information technology, software engineering and software reusability.

Currently, the challenge for preventing chronic diseases and for our investigation, $\mathrm{T} 2 \mathrm{D}$, is that there are few studies in this field for Canadian settings. Other international studies also confirm that prevention cannot be entirely cost-effective compared to treatment. This concern brings us to the following research question:

How can Information Technology help in healthcare to develop cost-effective prevention strategies for Type-2 Diabetes?

As the primary objective of this investigation, we attempt to examine if we can engineer a reusable software model which can facilitate the researchers in the future studies in the field of health economics or not.

Nevertheless, even if we can design such a model, it still is vital to make sure that future developers and engineers can extend and reuse parts of it, and as a result we need to make sure that our software is reusable, And for this purpose we will use the software reusability metrics we introduced in the methodologies section.

After the tests of reusability, we will use the software engineered to execute an RCT and compare the cost-effectiveness of two prevention programs of "Gym Incentives" and "Drug Group" with the control group not enrolled in any prevention program within the Canadian settings. 


\section{Software Proposal}

To this day, there have been various reports and papers in different countries and regions for healthcare programs' effectiveness. In each case, when the researchers and scientists attempt to study a specific aspect of healthcare. They must perform a set of tasks, which are always the same. For instance, the use of a Markov Model and Monte Carlo simulation is widespread in healthcare and medical field for managerial decision making.

Variables and their associated values in each study are different but the way a concept and model work, for instance, Markov Model, remains the same. In the field of healthcare, every study that relies on a Markov Model or Monte Carlo simulation, or any other mathematical methods, some steps are entirely repetitive, among them the development of methods and algorithms required to perform the calculations.

In this thesis, we propose the development of an open-source software package for the Canadian healthcare system, specialized in hosting different mathematical models and algorithms that can facilitate the way scientists conduct their studies. This Simulation Software can be hosted online and accessed online by all researchers worldwide.

As we discussed in the earlier part of this research, Software Reusability is an essential part of today's software engineering era, and for this reason, we will develop the proposed software with software reusability in mind to allow for future extension of the software package. 


\section{Methodologies}

There are several models and theories which help establish the grounds of this paper. This project will profoundly focus on mathematical calculations to forecast a future we need to be aware of far ahead of the time. Majority of the models and theories that we must benefit from are those of artificial intelligence area. Some of these models are as following:

\section{Software Reusability Metrics}

In the preview chapter, we proposed an open-source simulation software application. According to the types of software component we discussed earlier in literature review, any software component that can be internally investigated and modified by the developer is a White Box component, and as a result, we must evaluate our simulation software with the White Box reusability metrics.

\section{C.K Metrics:}

Chidamber \& Kemerer (1994) conducted a study and proposed software reusability metrics that are still in use and most elements of it remain accessible to this day. The authors proposed a software reusability metrics call C.K metrics and over the years there have been many reviews and adjustments over how the metrics work, and it has incorporated into many code metrics software suites such as NDepend v.2019 (ZEN PROGRAM LTD, 2019).

The following metrics are part of the proposed model: 


\section{A.1.1.11 Weighted Methods per Class (WMC)}

In a more recent study, H.M \& Nandakumar (2016) define WMC as the sum of complexity in a class. In whole, it signifies the complexity of the software classes and this measure can be used to identify the development and maintenance effort needed for the classes across the application.

Selvarani et al. (2009) define a good WMC value to be between 0 to 20 thresholds, a moderate to high WMC to be between 20 to 100, and any WMC above 100 requires investigation as it signifies a high-class complexity. WMC is a class ${ }^{9}$ level metric, and its value shows the classes and the relative number of methods. Classes with large numbers of methods are possibly more applicationspecific, and less likely to be reusable.

\section{A.1.1.12 Responses for a Class (RFC)}

H.M \& Nandakumar (2016) explain that RFC represents the number of growing and called methods within a set as a response to a message sent to an object performing a specific task.

The RFC is the set of internal and external methods which we can invoke in response to a message sent to an object of the class or a response to a message sent by a method in that class. RFC and complexity are directly related, and as the RFC increases, so will the ability to test, debug and maintain a class. For calculate on of RFC, inherited methods count, while overridden methods do not (Selvarani et al., 2009).

\footnotetext{
${ }^{9}$ A class is a set of objects sharing a common structure and a common behaviour manifested by the set of methods within that class (Selvarani et al., 2009).
} 


\section{A.1.1.13 Depth of Inheritance Tree (DIT)}

DIT is a frequently used metric in evaluating maintainability and reusability by estimating the extent of depth in the hierarchy of the classes (H.M \& Nandakumar, 2016).

This metric primarily evaluates efficiency and reuse but also relates to understandability and testability. The deeper the hierarchy of the class, the greater the number of methods it is likely to inherit become. The more methods a class inherits, the more complex it becomes, and it is difficult to predict its behaviour. Deeper hierarchies increase design complexity as well as the potential for reuse of inherited methods (Selvarani et al., 2009).

According to CachéQuality (2019), a DIT value of zero signifies a root class without any reuse or inheritance while a value of 2 or 3 signifies a higher degree of reuse.

\section{A.1.1.14 Number of Children (NOC)}

NOC measures the number of classes associated with a specific class through inheritance relationship. A class with many children suggests a bad class with bad design (H.M \& Nandakumar, 2016).

The more children a class has, the amount of reuse and the likelihood of improper parent abstraction increases, and it may be a sign of subclassing misuse (Selvarani et al., 2009).

\section{A.1.1.15 Coupling between Object Classes (CBO)}

$\mathrm{CBO}$ is the number of all other sets of classes for which a class couples with, and it is helpful in determining the complexity of the system during testing and reusability phases (H.M \& Nandakumar, 2016). 
Selvarani et al. (2009) define CBO as the strength of association established by a connection from one entity to another. The higher the value of this metric, the more sensitive the entities become to changes in other parts of the design; maintenance is, therefore, more difficult. For reusability, this metric should remain low.

\section{A.1.1.16 Lack of Cohesion of Methods (LCOM)}

Cohesion is the degree to which methods within a class are related to one another and work together to provide a well-bounded behaviour. An Effective object-oriented design maximizes cohesion as it promotes encapsulation. We can subdivide classes with low cohesion into subclasses with increased cohesion or increase the degree of similarity between their objects and properties. The more cohesive a design is, the more complex and reusable it can become (Selvarani et al., 2009).

\section{Markov Model}

Markov Model is a stochastic technique developed for randomly changing the system. This model is also known as a memoryless method that does not account for the previous states of the system and uses only the current state and one previous state to forecast the future states. It compares at least two different models, also known as groups in the same cycle length. The groups can be treatment and control groups (Kaelbling, Littman, \& Cassandra, 1998).

In this paper we will use Markov Model as a base for the development of our software package as this will enable us to see the value and costs associated with each approach as see which approach is more reasonable and why. 


\section{Monte Carlo Simulation}

There are situations where we cannot rely on approximate values, and we need precise values to make a managerial decision. Monte Carlo simulation will enable us to get all the possible exact results and outcomes of a specific model (Walter \& Barkema, 2015).

These simulations and techniques are often used in artificial intelligence to predict accurate outcomes when there are multiple unknown variables through repeated random sampling.

We will use this model to confirm our results further to calculate the expected costs of treatment and number of T2D cases that we will have to prevent the prevention program to be more costeffective.

\section{Cost-effectiveness analysis Theory (CEA)}

In a healthcare setting, the cost-effectiveness analysis will compare the expenses and output of two or more programs or initiatives that perform the same task (Bang \& Zhao, 2014).

We can use this theory to answer questions such as "Which method is the most cost-effective?" or "What is the most cost-effective approach?". We often express CEA as a ratio. The denominator is going to be units of a measure we gain as a result of the investment, and we are willing to compare that gain of units across two or more scenarios. The numerator in healthcare scenarios remains to be the costs associated with each program or investment (Bleichrodt \& Quiggin, 1999). The following formula demonstrates the calculation of the CEA:

$$
\frac{\text { Cost of the intervention }}{\text { Quality-Adjusted Life Years }}
$$




\section{Rational Choice Theory}

Rational choice theory is the outline to produce models of social and economic behaviour. This theory assumes that social behaviour is an accumulation of individuals' choices who have options to choose and make decisions based on those options (Allingham, 2002).

This model will allow us to understand why some people even though informed of their health conditions, are not participating in the prevention programs. This model will allow health care centers to address those barriers and issues to make that specific program more efficient. It is essential to mention that for a prevention program to be effective, attendance and participation of all sides is a crucial element to give us an accurate output. 


\section{Development Tools and Design Patterns}

\section{Microsoft SQL Server Express}

Microsoft SQL Server Express is a relational database management system that is free to download, distribute and use. We will use this software package to design a database for our software package to store the information of the study models and their parameters.

\section{Microsoft Visual Studio 2019 Community Edition}

A software development environment developed and released by Microsoft Corporation. We will use this IDE to develop the proposed simulation software using the ASP.NET Core MVC and C\# programming language (Microsoft Corporation, 2019b).

\section{A.1.1.17 ASP.NET Core MVC}

The ASP.NET Core MVC is an open-source framework optimized for use with ASP.NET Core. ASP.NET Core MVC provides a patterns-based way to build responsive web applications that promote the separation of concerns (Microsoft Corporation, 2019a).

\section{NDepend 2019 Extension for Visual Studio 2019}

NDepend is code metrics tools which we will use to calculate the C.K metrics of the software developed as part of this thesis (ZEN PROGRAM LTD, 2019).

\section{NodeJs}

An open-source, cross-platform and JavaScript run-time environment which promotes reusability and scalability of web applications and is highly adaptable to MVC and MVVM design patterns (Node.js Foundation, 2019). 


\section{React}

React is a JavaScript library developed by Facebook and is used in developing web user interfaces. It is primarily used to develop single-page applications (SPA) as it promotes a highly interactive interface (Facebook Inc., 2019).

\section{Redux}

Redux is a state management JavaScript library which we will incorporate into our application and works seamlessly with React library to improve the state management of our application (Dan Abramov, 2015).

\section{MVC Design Pattern}

The Model-View-Controller (MVC) is an architectural pattern that separates an application into three groups of components: Models, Views, and Controllers. MVC pattern promotes the concept of separation of concerns (Microsoft Corporation, 2019a). 


\section{First Software Milestone}

The first developed software milestone consists of several sections that help better define the aspects of a study and begin examining the effectiveness of it throughout the given cycles or years.

\section{Home page}

Home page, as the name implies, will be the first section the user will view upon accessing the application.

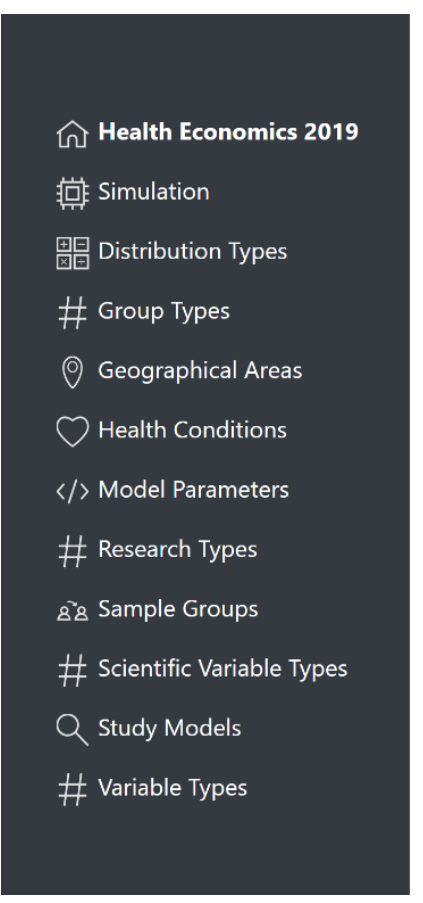

\section{WHAT IS SIMULATION?}

Simulation software is based on the process of modeling a real phenomenon with a set of mathematical formulas. It is, essentially, a program that allows the user to observe an operation through simulation without actually performing that operation.

\section{WHAT IS MARKOV MODEL?}

In probability theory, a Markov model is a stochastic model used to model randomly changing systems. It is assumed that future states depend only on the current state, not on the events that occurred before it.

\section{WHAT IS MONTE CARLO SIMULATION?}

Monte Carlo methods, or Monte Carlo experiments, are a broad class of computational algorithms that rely on repeated random sampling to obtain numerical results. The underlying concept is to use randomness to solve problems that might be deterministic in principle.

Figure 1 Simulation Software - Home Section 


\section{Research Types}

We define Research Types to give a bit of clarity to the project, and as of now, they do not affect the calculations. This section allows the researchers to categorize their study models for better understanding.

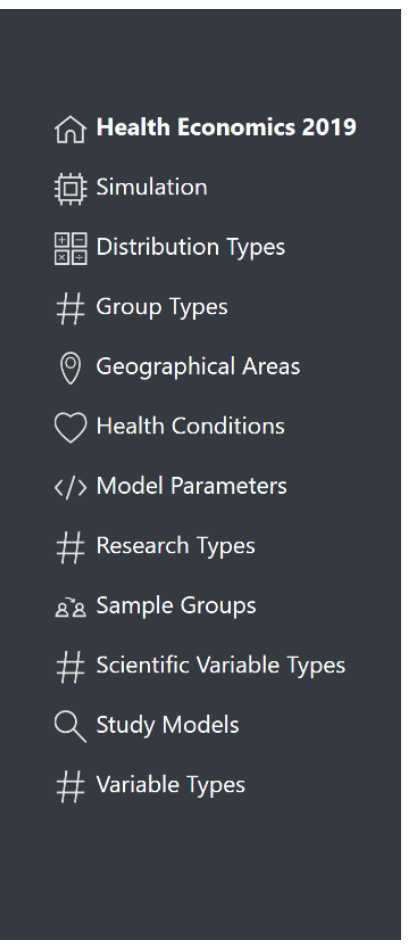

\section{LIST OF RESEARCH TYPES}

List below displays a list of all Research Types registered in the system.

\section{Add...}

\begin{tabular}{|c|c|c|c|}
\hline NAME & DESCRIPTION & ACTIONS & \\
\hline $\begin{array}{l}\text { Problem } \\
\text { Solving } \\
\text { Research }\end{array}$ & $\begin{array}{l}\text { This type of research is conducted by companies to } \\
\text { understand and resolve their own problems. The } \\
\text { problem-solving research uses applied research to find } \\
\text { solutions to the existing problems. }\end{array}$ & Edit & Delete \\
\hline $\begin{array}{l}\text { Problem } \\
\text { Oriented } \\
\text { Research }\end{array}$ & $\begin{array}{l}\text { As the name suggests, problem-oriented research is } \\
\text { conducted to understand the exact nature of the problem } \\
\text { to find out relevant solutions. The term "problem" refers } \\
\text { to having issues or two thoughts while making any } \\
\text { decisions. }\end{array}$ & Edit & Delete \\
\hline $\begin{array}{l}\text { Basic } \\
\text { Research }\end{array}$ & $\begin{array}{l}\text { Basic research is mostly conducted to enhance } \\
\text { knowledge. It covers fundamental aspects of research. }\end{array}$ & Edit & Delete \\
\hline
\end{tabular}

Figure 2 Simulation Software - Research Types Section

\section{Study Models}

In Study Models section, we will get to introduce the nature of the study we are planning to conduct, by defining its sample group and number of cycles and its parameters. 


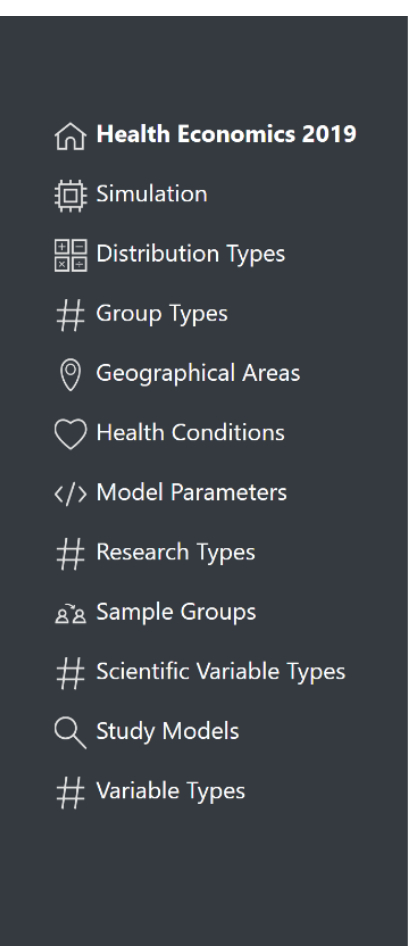

\section{LIST OF STUDY MODELS}

List below displays a list of all Study Models registered in the system.

\section{Add...}

\begin{tabular}{llll} 
NAME & RESEARCHABSTRACT & CYCLES & ACTIONS \\
\hline $\begin{array}{lll}\text { Diabetes } \\
\text { Intervention } \\
\text { Study in }\end{array}$ & $\begin{array}{l}\text { Objective In a randomized 5-yr multi- } \\
\text { intervention trial, we tested the efficacy of } \\
\text { intensified health education (IHE) in improving } \\
\text { GTA }\end{array}$ & & \\
& $\begin{array}{l}\text { metabolic control and reducing the level of } \\
\text { coronary risk factors and incidence of ischemic } \\
\text { heart disease (IHD). }\end{array}$
\end{tabular}

Figure 3 Simulation Software - Study Models Section

\section{Group Types}

For the nature of this application, we need to define the types of sample groups. Sample groups can be either control or treatment. 


\section{LIST OF GROUP TYPES}

List below displays a list of all Group Types registered in the system.

\section{Add...}

\begin{tabular}{lll} 
NAME & DESCRIPTION & ACTIONS \\
$\begin{array}{l}\text { Control } \\
\text { Group }\end{array}$ & $\begin{array}{l}\text { A control group is used as a baseline measure. The control group is } \\
\text { identical to all other items or subjects that you are examining with } \\
\text { the exception that it does not receive the treatment or the } \\
\text { experimental manipulation that the treatment group receives. For } \\
\text { example, when examining test tubes for catalytic reactions of } \\
\text { enzymes when added to a specific substrate, the control test tube } \\
\text { would be identical to all other test tubes with the exception of } \\
\text { lacking the enzyme. }\end{array}$ & Edit \\
\hline $\begin{array}{l}\text { Treatment } \\
\text { Group }\end{array}$ & $\begin{array}{l}\text { The treatment group is the item or subject that is manipulated. In } \\
\text { our example, all other test tubes containing enzyme would be part } \\
\text { of the treatment group. }\end{array}$ & Edit
\end{tabular}

Figure 4 Simulation Software - Group Types Section

\section{Sample Groups}

In this section, we define the actual sample groups, along with their descript. Please note that because the population of samples must be the same, samples within a study model will have the same number for population size inherited from their parent study model. 


\section{LIST OF SAMPLE GROUPS}

List below displays a list of all Sample Groups registered in the system.

\section{Add...}

NAME

ACTIONS

Gym Group

Control Group

Edit Delete

Drug Group

Figure 5 Simulation Software - Sample Groups Section

\section{Geographical Locations}

The geographical area is implemented as part of the plans for this research when we introduce more variables into the studies we conduct. As of now, this section only helps the completeness of the study model and does not affect the calculations. 


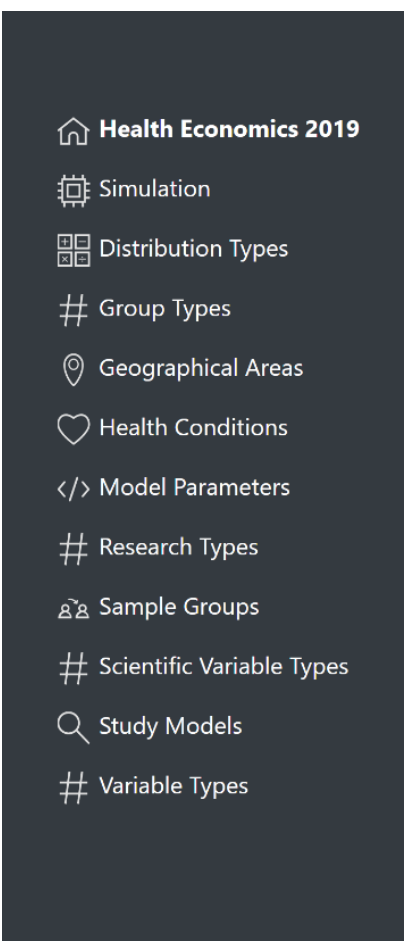

\section{LIST OF GEOGRAPHICAL AREAS}

List below displays a list of all Geographical Areas registered in the system.

\section{Add...}

\begin{tabular}{c|lllll}
\hline PROVINCE & NAME & COUNTRY & ACTIONS & \\
\hline Ontario & Belleville & Canada & Edit & Delete \\
\hline Ontario & Markham & Canada & Edit & Delete \\
\hline Ontario & Brampton & & Canada & Edit & Delete \\
\hline Ontario & Mississauga & & & \\
\hline Ontario & Ottawa (national capital) & Canada & Edit & Delete \\
\hline Ontario & Toronto (provincial capital) & Canada & Edit & Delete \\
\hline
\end{tabular}

Figure 6 Simulation Software - Geographical Locations Section

\section{Health Conditions}

This section will help the researcher define the health condition they plan to study. If they need to edit or remove a specific health condition, it is effortlessly accessible through the command buttons defined within the page. In Figure 7, we demonstrate a preview of the discussed section. 


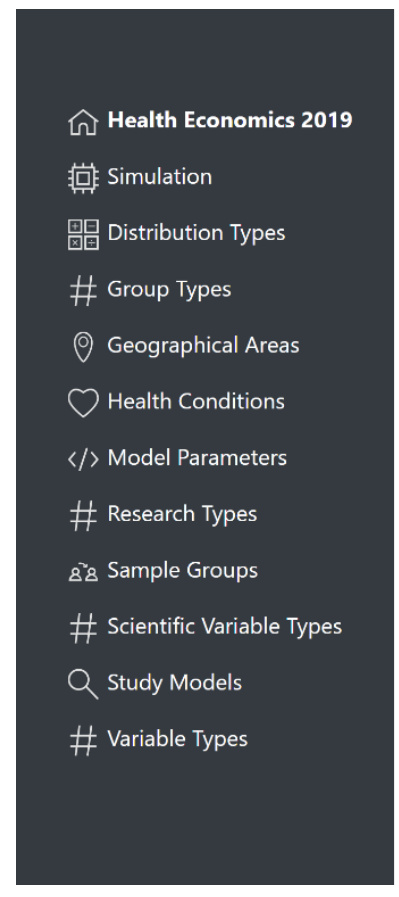

\section{LIST OF HEALTH CONDITIONS}

List below displays a list of all Health Conditions registered in the system.

\section{Add...}

\begin{tabular}{|c|c|c|c|}
\hline NAME & DESCRIPTION & ACTIONS & \\
\hline Arthritis & $\begin{array}{l}\text { Arthritis is inflammation or degeneration of one or more } \\
\text { joints. A joint is the area where } 2 \text { bones meet. There are } \\
\text { more than } 100 \text { different types of arthritis. }\end{array}$ & Edit & Delete \\
\hline Asthma & $\begin{array}{l}\text { Asthma is a disease that causes the airways of the lungs } \\
\text { to swell and narrow. It leads to wheezing, shortness of } \\
\text { breath, chest tightness, and coughing. }\end{array}$ & Edit & Delete \\
\hline $\begin{array}{l}\text { Chronic } \\
\text { obstructive } \\
\text { pulmonary } \\
\text { disease } \\
\text { (COPD) }\end{array}$ & $\begin{array}{l}\text { Chronic obstructive pulmonary disease (COPD) is a } \\
\text { common lung disease. Having COPD makes it hard to } \\
\text { breathe. }\end{array}$ & Edit & Delete \\
\hline Cancer & Cancer is the uncontrolled growth of abnormal cells in the & Edit & Delete \\
\hline
\end{tabular}

Figure 7 Simulation Software - Health Conditions Section

\section{Distribution Types}

The section "Distribution types" allows the researchers to define the list of probability distributions which they are going to use during the research. For the scope of this study, we have limited these definitions to Inverse Normal Distribution and Inverse Beta Distribution used in the calculation of our Markov Model. Figure 8 displays a preview of this section: 


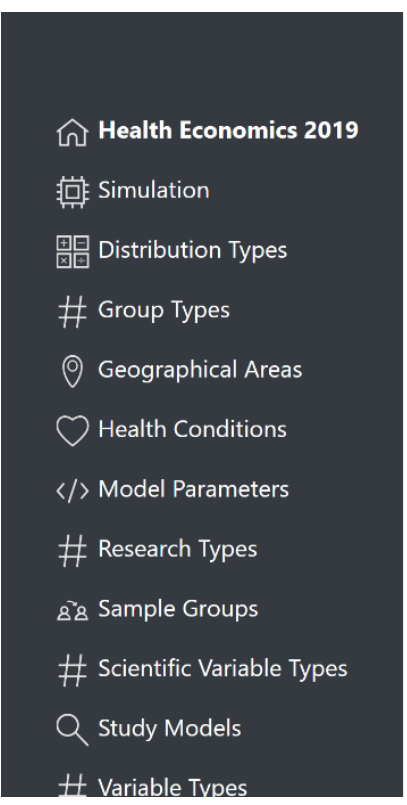

\section{LIST OF DISTRIBUTION TYPES}

List below displays a list of all Distribution Types registered in the system.

$$
\text { Add... }
$$

\begin{tabular}{|c|c|c|c|}
\hline NAME & DESCRIPTION & ACTIONS & \\
\hline None & None. & Edit & Delete \\
\hline $\begin{array}{l}\text { Normal } \\
\text { inverse }\end{array}$ & $\begin{array}{l}\text { The inverse distribution function for continuous variables } \\
\mathrm{Fx}-1(\alpha) \text { is the inverse of the cumulative distribution }\end{array}$ & Edit & Delete \\
\hline
\end{tabular}

cumulative function (CDF). In other words, it's simply the distribution

distribution function $\mathrm{Fx}(\mathrm{x})$ inverted. The CDF shows the probability a

random variable $X$ is found at a value equal to or less than

a certain $x$

Normal In probability theory, the normal (or Gaussian or Gauss or

cumulative I anlace-Gauss) distrihution is a verv rommon continunus

Figure 8 Simulation Software - Distribution Types Section

\section{Model Parameters}

The Model Parameters section in the primary hub to define all the model parameters, overall sample groups. Using this panel, we can define the type of parameter, describe how it works or define a formula for it. 


\section{凡ิ Health Economics 2019}

涪 Simulation

増 Distribution Types

\# Group Types

() Geographical Areas

Health Conditions

$</>$ Model Parameters

\# Research Types

8s Sample Groups

\# Scientific Variable Types

Q Study Models

\# Variable Types

\section{LIST OF MODEL PARAMETERS}

List below displays a list of all Model Parameters registered in the system.

\section{Add...}

\begin{tabular}{llll} 
NAME & DESCRIPTION & ACTIONS \\
\hline Prog & $\begin{array}{l}\text { Progressive disease or progressive illness is a disease or } \\
\text { physical ailment whose course in most cases is the } \\
\text { worsening, growth, or spread of the disease. This may } \\
\text { happen until death, serious debility, or organ failure } \\
\text { occurs. Some progressive diseases can be halted and } \\
\text { reversed by treatment. }\end{array}$ & Edit & Delete \\
\hline DEATH_RISK & $\begin{array}{l}\text { Natural death risk for under 35's (from standard life- } \\
\text { tables) }\end{array}$ & Edit & Delete \\
\hline Population & $\begin{array}{l}\text { The sample size. } \\
\text { Prog }\end{array}$ & $\begin{array}{l}\text { Progressive disease or progressive illness is a disease or } \\
\text { physical ailment whose course in most cases is the }\end{array}$ & Edit \\
\hline
\end{tabular}

physical ailment whose course in most cases is the

worsenina. arowth. or sbread of the disease. This mav

Figure 9 Simulation Software - Model Parameters Section

\section{Variable Types}

This section allows you to define the variable types. A variable type helps the simulation software

to use the proper mathematical methods such as distribution types when computing the models. 


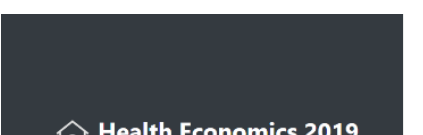

\section{LIST OF VARIABLE TYPES}

\section{溤 Simulation}

増 Distribution Types

\# Group Types

(2) Geographical Areas

$\bigcirc$ Health Conditions

</> Model Parameters

\# Research Types

8 s. Sample Groups

\# Scientific Variable Types

Q Study Models

\# Variable Types
List below displays a list of all Variable Types registered in the system.

\section{Add...}

\begin{tabular}{l|ll}
\hline NAME & ACTIONS & \\
\hline Range & Edit & Delete \\
\hline Decimal & Edit & Delete \\
\hline Percentage & Edit & Delete \\
\hline Currency & & \\
\hline Integer & Edit & Delete \\
\hline String & & \\
\hline
\end{tabular}

Figure 10 Simulation Software - Variable Types Section

\section{Scientific Variable Types}

Define the correct scientific variable types is vital as the simulation software categorizes the parameters based on this factor. Scientific variable types can be dependent, independent, controlled or extraneous. 
囚 Health Economics 2019

損 Simulation

暍 Distribution Types

\# Group Types

○ Geographical Areas

$\checkmark$ Health Conditions

</> Model Parameters

\# Research Types

8\%8 Sample Groups

\# Scientific Variable Types

Q Study Models

\# Variable Types

\section{LIST OF SCIENTIFIC VARIABLE TYPES}

List below displays a list of all Scientific Variable Types registered in the system.

\section{Add..}

\begin{tabular}{l|l|l|l|l|l|} 
NAME & DESCRIPTION & ACTIONS \\
\hline Dynamic & $\begin{array}{l}\text { this variable accepts formula and overrides the value of } \\
\text { another variable. }\end{array}$ & Edit & Delete \\
\hline None & Functions such as ranges will be defined in this category. & Edit & Delete \\
\hline Extraneous & $\begin{array}{l}\text { Extraneous variables are "extra" variables that may } \\
\text { influence the outcome of an experiment but aren't taken }\end{array}$ & Edit & Delete \\
\hline
\end{tabular}

into account during measurement. Ideally, these variables won't impact the final conclusion drawn by the experiment, but they may introduce error into scientific results. If you are aware of any extraneous variables, you should enter them in your lab notebook. Examples of extraneous variables include accidents, factors you either can't control or can't measure or factors you consider unimportant. Everv experiment has extraneous

Figure 11 Simulation Software - Scientific Variables Section

\section{Simulation}

The most important part of this software is the simulation page. It allows the researcher to compare the results of their intervention through a responsive plot using the variable of their choice. We can also download the comma-separated values file (CSV) of the graph through the available options on this section. 
๙ิ Health Economics 2019

浯 Simulation

鰨 Distribution Types

\# Group Types

○ Geographical Areas

$\checkmark$ Health Conditions

$\langle/\rangle$ Model Parameters

\# Research Types

8\%8 Sample Groups

\# Scientific Variable Types

Q Study Models

\# Variable Types

\section{A MARKOV MODEL OF ALL GROUPS DEFINED FOR THE STUDY}

The chart below displays the outcome for variable 'Prog'.

Prog : Progressive disease or progressive illness is a disease or physical ailment whose course in most cases is the worsening, growth, or spread of the disease. This may happen until death, serious debility, or organ failure occurs. Some progressive diseases can be halted and reversed by treatment.

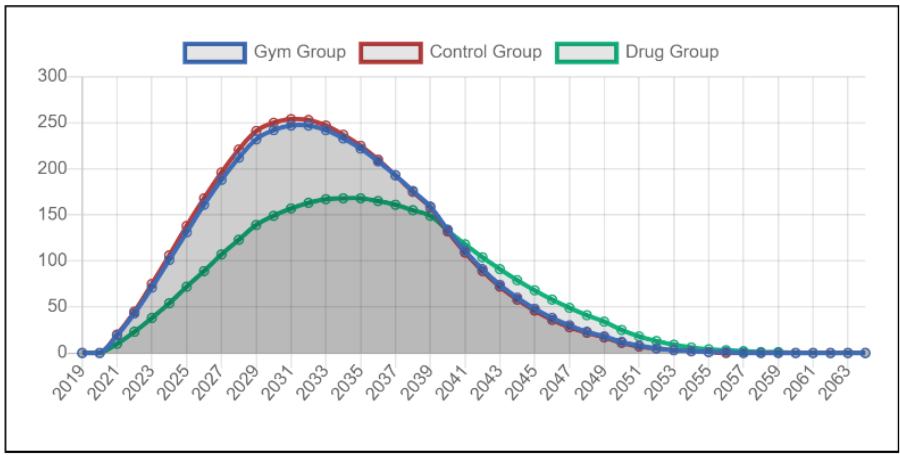

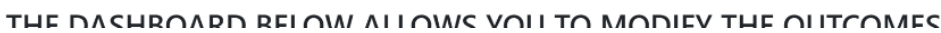

Figure 12 Simulation Software - Simulation Section

\section{Simulation Dashboard}

Dashboard section is an extension to the simulation page. It allows the researchers to dynamically update the controlled variables of the study, change the variable being compared across the sample groups and update the results instantly. 


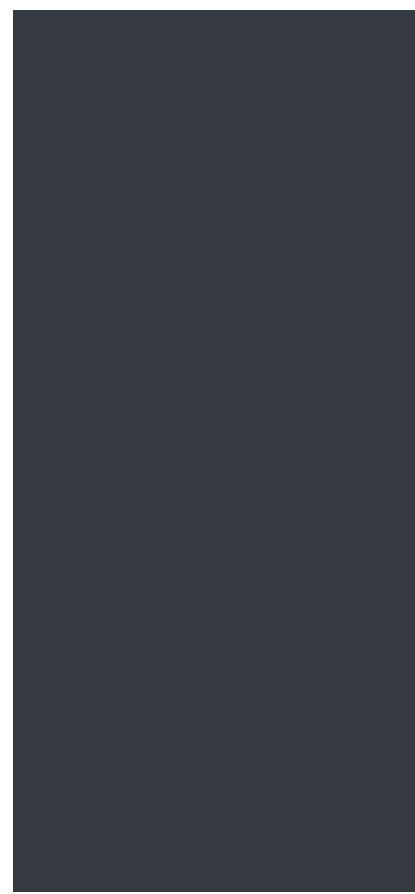

THE DASHBOARD BELOW ALLOWS YOU TO MODIFY THE OUTCOMES.

Population of the groups

Cost / Asymp. State

1000

Gym Membership (\$)

500

Initial age of the group

participants

30

55

Drug Costs

1000

Cost / Terminal stage

Effectiveness of the drug

1000

0.5

Exercise Outcomes

0.05

List of variables to compare

Disease Progressio

Update

Figure 13 Simulation Software - Simulation Dashboard Section 


\section{Software Reusability Test Results}

In this chapter, we will use C.K metrics and the NDepend 2019 Extension for Visual Studio 2019 to evaluate the reusability of the proposed and developed software. Please note we have attached all the scripts which were used to produce the results in the appendices section.

\section{WMC Metric Result}

Figure 14 illustrates a list of classes with $20<\mathrm{WMC}<=100$.

7 types

wmc

7 types matched

4 HealthEconomics (7types)

4 (\}) HealthEconomics.DataModels (1 type)

iș ModelParameter

4 \{\} HealthEconomics.Controllers (1 type)

iș ModelsController

4 \{\} HealthEconomics.SimulationPackages.MarkovModel (1 type)

¿s MarkovModel

4 \{\} HealthEconomics.DatabaseAccessLayers (1 type)

is DatabaseAccessLayer

4 \{\} HealthEconomics.SimulationPackages.MonteCarloSimulation (1 type)

iș MonteCarloSimulation

(\}) HealthEconomics.Helpers (2 types)

बै। PropertyExtensions

बढ़ TypeExtensions

Figure 14 Classes with " $20<W M C<=100$ "

Figure 15 demonstrates a list of classes with $20<=$ WMC $<=100$. 


\section{0 types matched}

4 HealthEconomics (30 types)

4 (\}) HealthEconomics.DataModels (10 types)

¿ढ़ StudyModel



¿६ GeographicalArea

is HealthCondition

¿ DistributionType

¿sperimentGroupType

ResearchType

¿ts ScientificVariableType

« MainContext

* VariableType

4 (\}) HealthEconomics.Helpers (8types)

$$
\begin{aligned}
& \text { 단 MathExtensions } \\
& \text { L़ StringExtensions } \\
& \text { ót MarkovModelExtensions } \\
& \text { ót DatabaseExtensions } \\
& \text { 난 NCalcExtensions } \\
& \text { (ए) PresetDataGenerator } \\
& \text { J' JsonExtensions } \\
& \text { Its ModelExtensions }
\end{aligned}
$$

4 (\}) HealthEconomics.SimulationPackages.MonteCarloSimulation (2 types)

६६ SimulationResultsHolder

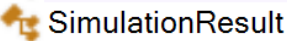

4 (\}) HealthEconomics.SimulationPackages.MarkovModel (2 types)

MarkovModelResult

MarkovModelGroupsResults

4 (\}) HealthEconomics.Pages (1 type)

is ErrorModel

4 (\}) HealthEconomics.DataModels.GenericDefinitions (5 types)

¿șaseModel

JsonKeyValue

¿\$ FieldInfo

is Modellnfo

¿ ModelSpecs

4 (\}) HealthEconomics (1 type)

¿\$ Program

4 \{\} HealthEconomics.Controllers (1 type)

is ModelParameterBinder

Figure 15 Classes with " $1<=W M C<=20$ " 
There were no classes within the solution which had a WMC value greater than 100 . The overall WMC values displays a low to moderate class complexity which provides a good opportunity for reuse and maintenance.

\section{RFC Metric Result}

Figure 16 demonstrates a list of classes with their associated RFC values, direct and indirect method calls. To keep the figure size standard and readable, we have removed the classes with no methods and RFC value of 0 . Even though most of the classes have a low RFC value, classes such as "DatabaseAccessLayer" or "MonteCarloSimulation" require a moderate level of understanding of the code for the software developer to test and debug the program.

\begin{tabular}{|c|c|c|c|}
\hline 47 types & methodsUsedDirectly & methodsUsedIndirect & rfc \\
\hline \multicolumn{4}{|l|}{47 types matched } \\
\hline 4 HealthEconomics (47types) & & & \\
\hline is DatabaseAccessLayer & 12 methods & 97 methods & 97 \\
\hline ModelsController & 40 methods & 95 methods & 95 \\
\hline ث̧ Program & 2 methods & 95 methods & 95 \\
\hline बैड PresetDataGenerator & 64 methods & 82 methods & 82 \\
\hline is MonteCarloSimulation & 9 methods & 51 methods & 51 \\
\hline बी़ MarkovModelExtensions & 9 methods & 46 methods & 46 \\
\hline tş MarkovModel & 18 methods & 30 methods & 30 \\
\hline बीड़ DatabaseExtensions & 6 methods & 20 methods & 20 \\
\hline Q Model Extensions & 7 methods & 14 methods & 14 \\
\hline ¿६ ModelSpecs & 1 method & 10 methods & 10 \\
\hline \$\$ ModelParameterBinder & 2 methods & 8 methods & 8 \\
\hline อ̆ NCalcExtensions & 5 methods & 5 methods & 5 \\
\hline MathExtensions & 4 methods & 4 methods & 4 \\
\hline L̨̧ Research Type & 1 method & 3 methods & 3 \\
\hline ExperimentGroupType & 1 method & 3 methods & 3 \\
\hline ¿६ GeographicalArea & 1 method & 3 methods & 3 \\
\hline HealthCondition & 1 method & 3 methods & 3 \\
\hline « StudyModel & 1 method & 3 methods & 3 \\
\hline ¿ VariableType & 1 method & 3 methods & 3 \\
\hline \& ModelParameter & 1 method & 3 methods & 3 \\
\hline is ScientificVariableType & 1 method & 3 methods & 3 \\
\hline "⿺ MarkovModelGroupsResults & 3 methods & 3 methods & 3 \\
\hline Tş SampleGroup & 1 method & 3 methods & 3 \\
\hline Mais MainContext & 1 method & 3 methods & 3 \\
\hline 伭 DistributionType & 1 method & 3 methods & 3 \\
\hline बैं TypeExtensions & 2 methods & 2 methods & 2 \\
\hline ¿ BaseModel & 1 method & 2 methods & 2 \\
\hline ฮी JsonExtensions & 1 method & 1 method & 1 \\
\hline SimulationResultsHolder & 1 method & 1 method & 1 \\
\hline
\end{tabular}

Figure 16 RFC Value for classes across the solution 


\section{DIT Metric Result}

Figure 17 displays only a list of classes which inherited from a base class. We removed the root classes from the list generated to keep the list short. According to the earlier discussion, the value of DIT being 2, signifies a reasonable and higher degree of reuse. Please note that values higher than three does not automatically signify better reuse, and on the contrary can cause overly complicated code structure (Selvarani et al., 2009).

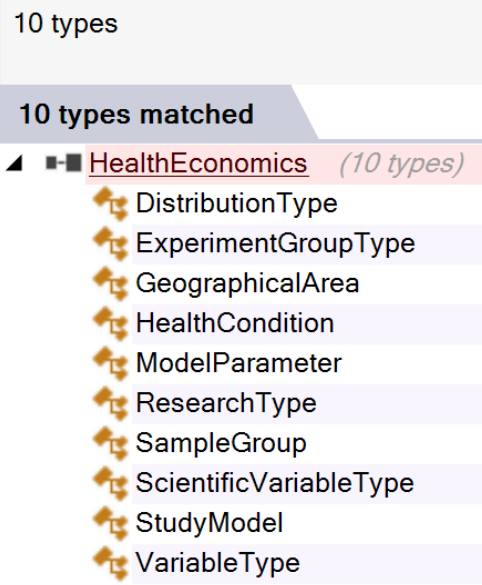

1 type $\quad 2$

Figure 17 DIT Value for classes across the solution

\section{NOC Metric Result}

Figure 18 displays the result of the NOC metric test across the software solution returning only one class with ten children/inherited classes. In this case, the solution is easily maintainable and changeable. 


\section{7 types matched}

4 HealthEconomics (1 type)

६६ BaseModel

10 types

D-ISystem.Runtime (8 types)

$\nabla$ mscorlib (2 types)

D-nstem.Collections (1 type)

microsoft.AspNetCore.Mvc.Core (1 type)

D-m Microsoft.AspNetCore.Mvc.RazorPages (1 type)

Dicrosoft.EntityFrameworkCore (1 type)

D-Wystem.Linq.Expressions (1 type)

D-Microsoft.AspNetCore.Mvc.ViewFeatures (1 type)

Figure 18 NOC Value for the HealthEconomics Solution

\section{CBO Metric Result}

Figure 19 demonstrates the value $\mathrm{CBO}$ metric for each of the classes across the solution with most of the classes having a very low $\mathrm{CBO}$ compared to the classes "ModelsController" and "PresetDataGenerator."

"PresetDataGenerator" is responsible for generating dummy data for testing, and we can remove it from the project without affecting the functionality of the software. Please note that we removed the classes with $\mathrm{CBO}$ value of zero from the list.

Class "ModelsController" is the main entrance to the web application for client users accessing the website. It can be divided into different MVC controllers once the cohesion becomes low within that class. Overall the project displays a good $\mathrm{CBO}$ value, meaning that there is low coupling across the classes which promotes maintainability and reusability. 
48 types matched

\begin{tabular}{|c|c|}
\hline tis ModelsController & 23 types \\
\hline @! PresetDataGenerator & 13 types \\
\hline Mode Modextensions & 10 types \\
\hline MonteCarloSimulation & 10 types \\
\hline (t5 MarkovModelExtensions & 9 types \\
\hline DatabaseExtensions & 8 types \\
\hline tॄ় ModelParameter & 7 types \\
\hline ¿̦ DatabaseAccessLayer & 6 types \\
\hline "⿺ş MarkovModel & 6 types \\
\hline StudyModel & 6 types \\
\hline SampleGroup & 5 types \\
\hline L DistributionType & 3 types \\
\hline ¿sp ExperimentGroupType & 3 types \\
\hline ¿दs GeographicalArea & 3 types \\
\hline HealthCondition & 3 types \\
\hline t\$ ResearchType & 3 types \\
\hline ¿ş ScientificVariableType & 3 types \\
\hline ¿ VariableType & 3 types \\
\hline ț BaseModel & 3 types \\
\hline \&s Program & 2 types \\
\hline 누 MathExtensions & 2 types \\
\hline 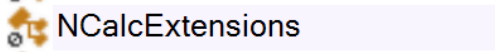 & 2 types \\
\hline TypeExtensions & 2 types \\
\hline "६̧ MarkovModelGroupsResults & 2 types \\
\hline t६़ MainContext & 2 types \\
\hline ţ ModelSpecs & 2 types \\
\hline Øடு JsonExtensions & 1 type \\
\hline 단 PropertyExtensions & 1 type \\
\hline ৫\$ ModelParameterBinder & 1 type \\
\hline Ts MonteCarloSimulationResults & 1 type \\
\hline 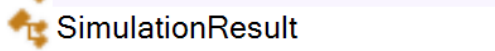 & 1 type \\
\hline ¿s SimulationResultsHolder & 1 type \\
\hline "६̧ FieldInfo & 1 type \\
\hline
\end{tabular}

Figure 19 CBO Value for classes across the solution

\section{LCOM Metric Result}

Figure 20 Demonstrates a graph of Lack of Cohesion of Methods (LCOM) generated by NDepend 2019 Extension for Visual Studio 2019. Majority of classes display a low value for "Lack of Cohesion of Methods," which is a desirable result for reusable software. We did not find any 
classes or types having a high LCOM value. The low LCOM value fundamentally means that the classes across the solution have high cohesion of methods and that their methods are relevant to each other and work together.

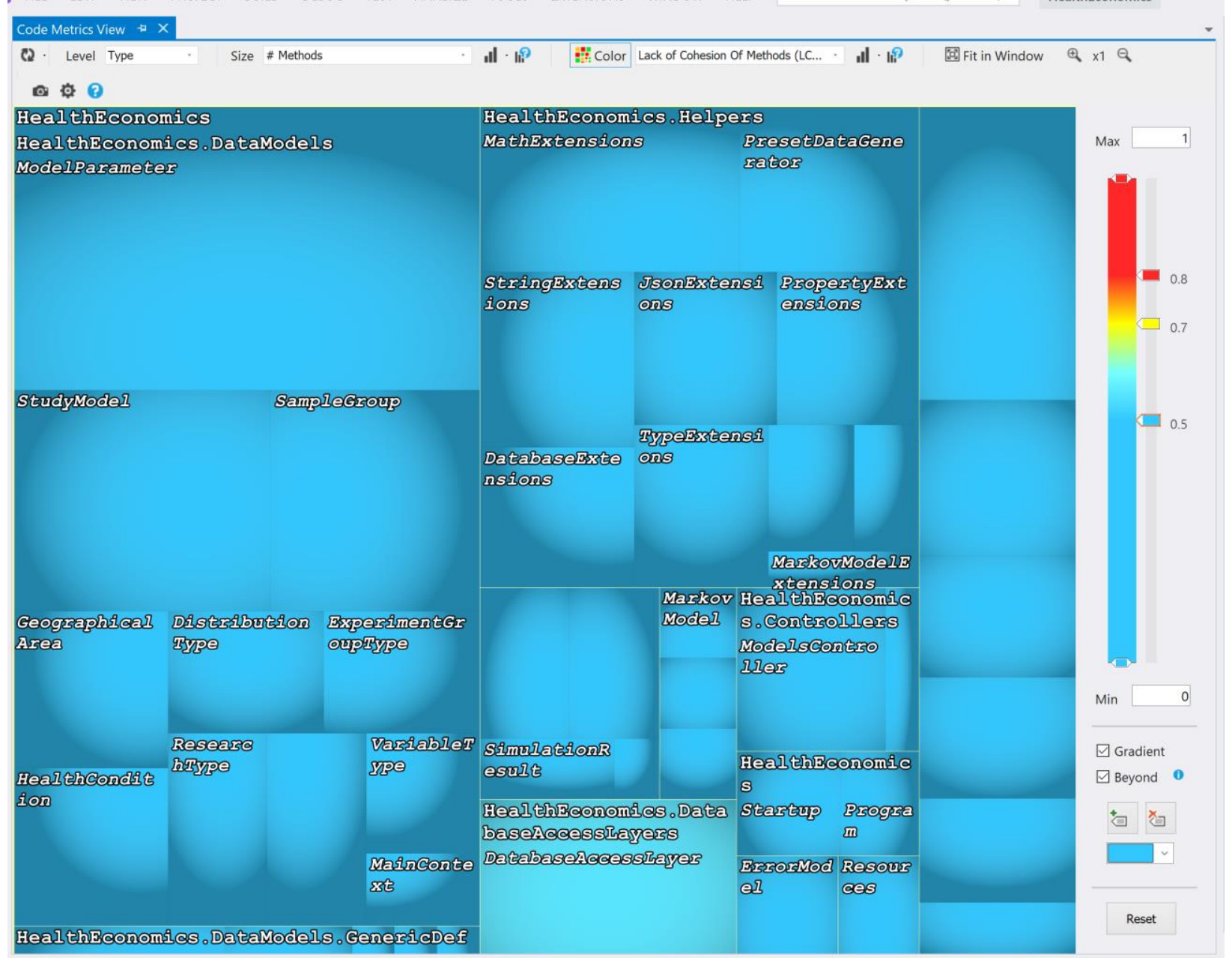

Figure 20 LCOM graph for the HealthEconomics Solution generated by NDepend 2019 (ZEN PROGRAM

LTD, 2019) 


\section{Discussion of Metrics Results}

Table 5 demonstrates the overall result of the six different metrics tests. We can conclude that according to the results of this test, the first milestone of the proposed software is reusable, maintainable, adaptable and testable.

\begin{tabular}{lll} 
Metric & Result & Comments \\
\hline CBO & Low coupling & $\begin{array}{l}\text { Maintainable } \\
\text { Reusable }\end{array}$ \\
\hline DIT & Moderate Inheritance, Promotes & $\begin{array}{l}\text { Reusable } \\
\text { Understandable }\end{array}$ \\
\hline LCOM & Low Lack of Cohesion & Reusable \\
\hline NOC & Low Number of Children & $\begin{array}{l}\text { Maintainable } \\
\text { Adaptable } \\
\text { Reusable }\end{array}$ \\
\hline RFC & $\begin{array}{l}\text { Moderate level of classes' complexity and } \\
\text { communication with each other }\end{array}$ & $\begin{array}{l}\text { Average Level of Understanding } \\
\text { Required To Test And Debug }\end{array}$ \\
\hline WMC & Moderate Complexity & \begin{tabular}{l} 
Reusable \\
\hline
\end{tabular}
\end{tabular}

Table 5 Results of the Reusability Metrics Test 


\section{First Simulation}

As we stated in the research question, we plan to put our simulation software to the test and perform an RCT to see if we can achieve cost-effectiveness of prevention for T2D in Canadian Healthcare settings during a 10-Year time horizon from the year 2019 until the year 2029.

We will attempt to compare the cost-effectiveness of two separate interventions with a control group across the Greater Toronto Area (GTA) and investigate which approach brings more social value aside from monetary benefits. The following will be our intervention groups:

\section{Gym Group}

We provide this group with a gym membership at Humber River Hospital that costs CAD 65.00 for six months of membership before taxes. Using this strategy, we aim at promoting exercise and physical activity across the group population. According to the Canadian Diabetes Association (2019), 150 minutes of moderate to vigorous aerobic exercise weekly can be as effective as medication. Please note that we only used the price and numbers from the above to simulate the study outcomes, and we did not conduct a gym incentive program in the real-world setting.

\section{Medication Group}

Medication group is a group of patients receiving the medication (Metformin) as a form of intervention.

\section{Choice of Variables}

The variables in the simulation software are very similar to those of the Markov Model designed by Briggs et al. (2006). However, we have adjusted all the prices to Canadian Dollars. Table 4, 
which we introduced in the literature review, reveals the annually inflation-adjusted costs associated with Type 2 Diabetes for each patient in Canada.

Based on the latest report by Statistics Canada (2019), the prevalence of diabetes across the Canadian population is $7.1 \%$ of the entire community, which is equal to 435,898 of GTA population. Nevertheless, for the scope of this study, we have to start with prevention strategy, which is realistic and testable, and as such, we have decided to conduct this analysis with a 5,000sample size per each group.

According to a study by Marinho et al. (2018), authors revealed that the adherence to physical activity and exercise is only $22.5 \%$ while the adherence to medication is a whopping $93.5 \%$. We will include the adherence values and expect to observe differences in the outcome of the Gym and Medication Group.

\section{List of Variables Used in the model}

\begin{tabular}{l|l|l|l|l} 
Name & \multicolumn{2}{l}{ Description } & Rource & Mean \\
\hline $\begin{array}{l}\text { Acute/Progressive } \\
\text { Disease Cost }\end{array}$ & $\begin{array}{l}\text { Annual Cost of disease in the } \\
\text { progressive state for each } \\
\text { patient }\end{array}$ & $\begin{array}{l}\text { Canadian Institute for } \\
\text { Health Information } \\
(2007)\end{array}$ & $\begin{array}{l}\text { CAD } \\
4,478.19\end{array}$ & CAD 4,478.19 \\
\hline $\begin{array}{l}\text { Age of Participants } \\
\text { Asymptomatic Disease }\end{array}$ & $\begin{array}{l}\text { Annual Cost of disease in the } \\
\text { participants enter the program } \\
\text { asymptomatic state for each } \\
\text { patient }\end{array}$ & $\begin{array}{l}\text { Government of Canada } \\
(2017)\end{array}$ & 40 & 40 \\
\hline $\begin{array}{l}\text { Bilandzic \& Rosella } \\
(2017)\end{array}$ & CAD & $1,302.76$ & CAD 1,302.76 \\
\hline Cost of Drug & Annual Cost of Metformin & $\begin{array}{l}\text { Drugs and Technologies } \\
\text { in Health (2018) }\end{array}$ & $\begin{array}{l}\text { CAD } \\
107.98\end{array}$ & CAD 107.98 \\
\hline
\end{tabular}




\begin{tabular}{|c|c|c|c|c|}
\hline $\begin{array}{l}\text { Cost of Gym } \\
\text { Membership Annually }\end{array}$ & $\begin{array}{l}\text { CAD } 65.00 \text { for six months of } \\
\text { membership before taxes. }\end{array}$ & $\begin{array}{l}\text { Humber River Hospital } \\
\text { (2019) }\end{array}$ & $\begin{array}{l}\text { CAD } \\
146.9\end{array}$ & CAD 146.9 \\
\hline Diabetic Percentage & $\begin{array}{l}\text { Percentage of type } 2 \text { diabetic } \\
\text { individuals in Canada. }\end{array}$ & Statistics Canada, (2019) & $7.1 \%$ & $7.1 \%$ \\
\hline Exercise Adherence & $\begin{array}{l}\text { Adherence of individuals to } \\
\text { exercise and physical activity } \\
\text { required for controlling their } \\
\text { condition }\end{array}$ & Marinho et al. (2018) & $22.5 \%$ & $22.5 \%$ \\
\hline Medication Adherence & $\begin{array}{l}\text { Adherence of individuals to } \\
\text { medication required for } \\
\text { controlling their condition }\end{array}$ & Marinho et al. (2018) & $93.5 \%$ & $93.5 \%$ \\
\hline $\begin{array}{l}\text { Effectiveness of } \\
\text { Medication }\end{array}$ & $\begin{array}{l}\text { Likelihood of Medication } \\
\text { controlling the symptom of the } \\
\text { disease. }\end{array}$ & Briggs et al. (2006) & $\begin{array}{l}40 \%-60 \% \\
\times \\
\text { Medication } \\
\text { Adherence }\end{array}$ & $\begin{array}{l}50 \% \times \\
\text { Medication } \\
\text { Adherence }\end{array}$ \\
\hline Effectiveness of Gym & $\begin{array}{l}\text { Likelihood of Gym controlling } \\
\text { the symptom of the disease. }\end{array}$ & $\begin{array}{l}\text { Canadian Diabetes } \\
\text { Association (2019) }\end{array}$ & $\begin{array}{l}40 \%-60 \% \\
\times \text { Exercise } \\
\text { Adherence }\end{array}$ & $\begin{array}{l}50 \% \times \\
\text { Exercise } \\
\text { Adherence }\end{array}$ \\
\hline GTA Population & $\begin{array}{l}\text { Population of Greater Toronto } \\
\text { Area }\end{array}$ & $\begin{array}{l}\text { World Population } \\
\text { Review (2019) }\end{array}$ & $6,139,404$ & $6,139,404$ \\
\hline Sample Size & $\begin{array}{l}\text { Diabetic Percentage X GTA } \\
\text { Population }\end{array}$ & N/A & 435,898 & 435,898 \\
\hline Terminal Cost & $\begin{array}{l}\text { The cost associated with the } \\
\text { death of a patient }\end{array}$ & $\begin{array}{l}\text { Tanuseputro et al. } \\
\text { (2015) }\end{array}$ & $\begin{array}{l}\text { CAD } \\
57,749.86\end{array}$ & $\begin{array}{l}\text { CAD } \\
57,749.86\end{array}$ \\
\hline
\end{tabular}

Table 6 Variables and Values used for simulation 


\section{Results}

In this section, we first demonstrate the results of the first simulation using the variables and values defined in the previous section and finally, we proceed to discuss the results of these simulations.

\section{Markov Model Results}

\section{A.1.1.18 A Preview of The Dashboard Variables}

The following figure demonstrates an interactive panel that allows us to enter the variables and update the simulation dynamically.

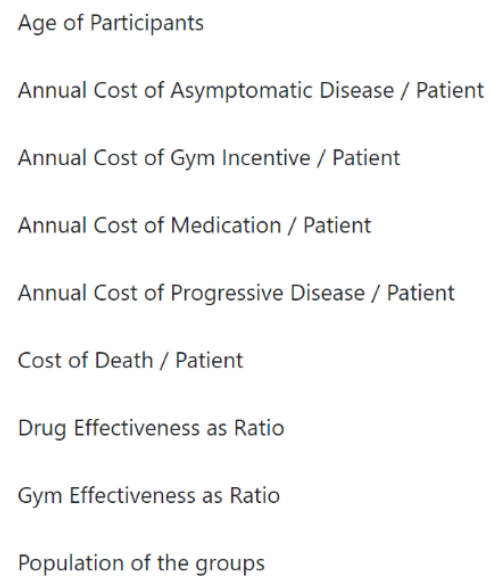

\begin{tabular}{|l|}
\hline 40 \\
\hline 1302.76 \\
\hline 146.9 \\
\hline 107.98 \\
\hline 4478.19 \\
\hline 57749.86 \\
\hline 0.4675 \\
\hline 0.1125 \\
\hline 5000 \\
\hline
\end{tabular}

Figure 21 Overview of The Dashboard Values of The First Simulation 


\section{A.1.1.19 Number of Individuals in an Asymptomatic State of Disease Across All Groups}

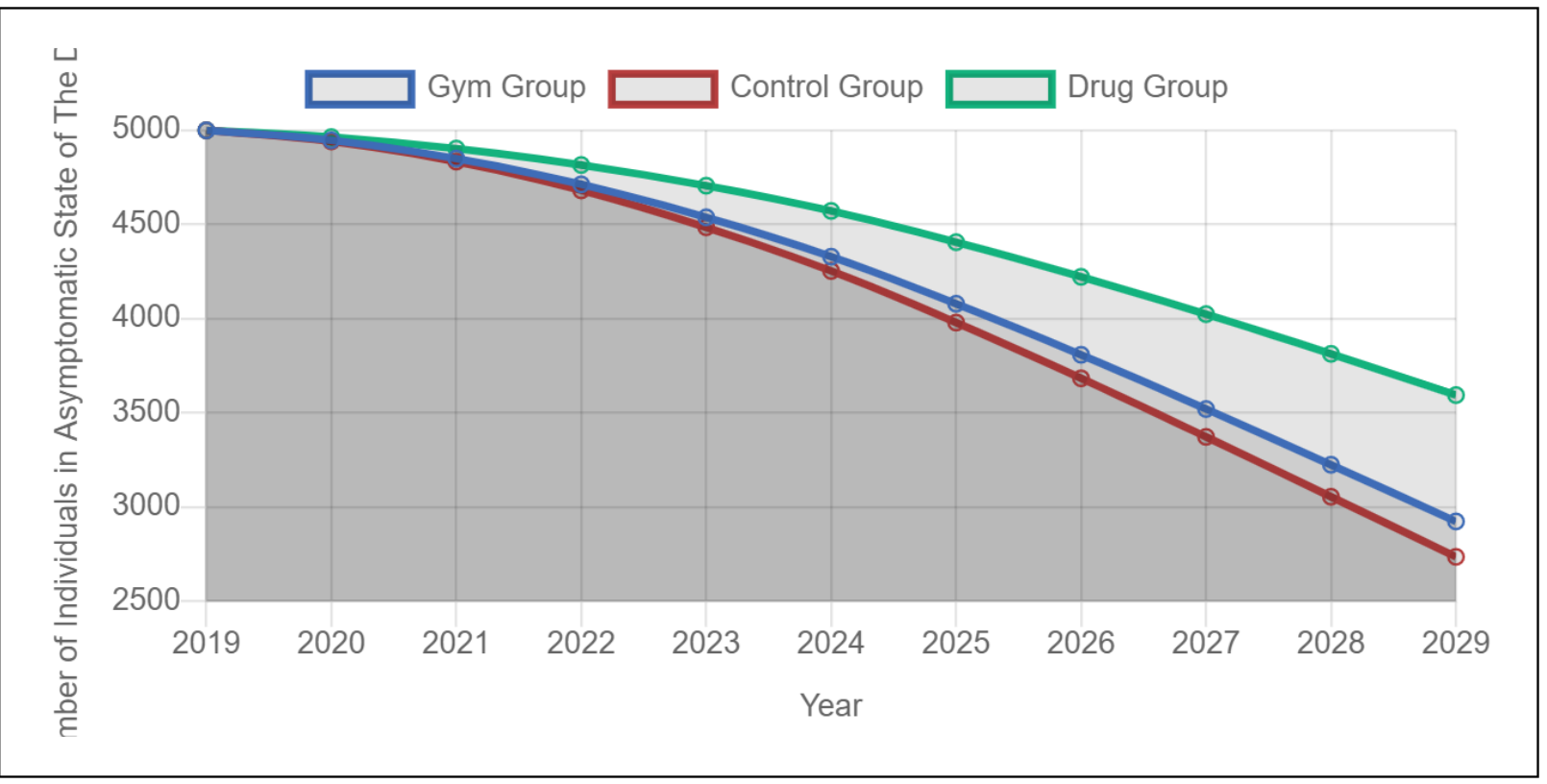

Figure 22 Plot of The Total Number of Individuals in an Asymptomatic Stage of the Disease

\section{A.1.1.20 Number of Individuals in a Progressive State of Disease Across All Groups}

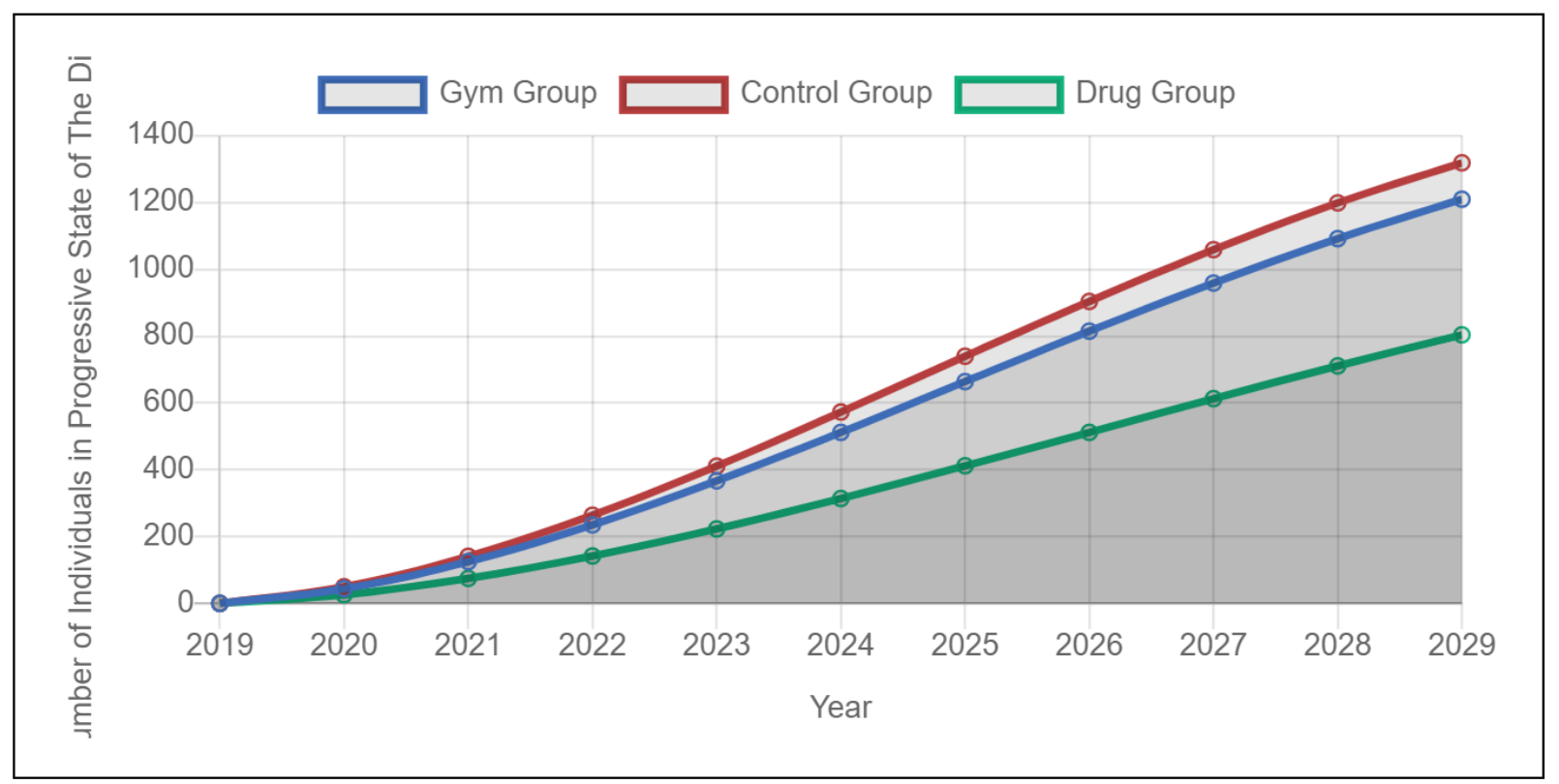

Figure 23 Plot of The Total Number of Individuals in a Progressive State of the Disease 


\section{A.1.1.21 Quality-Adjusted Life-Years Across All Groups}

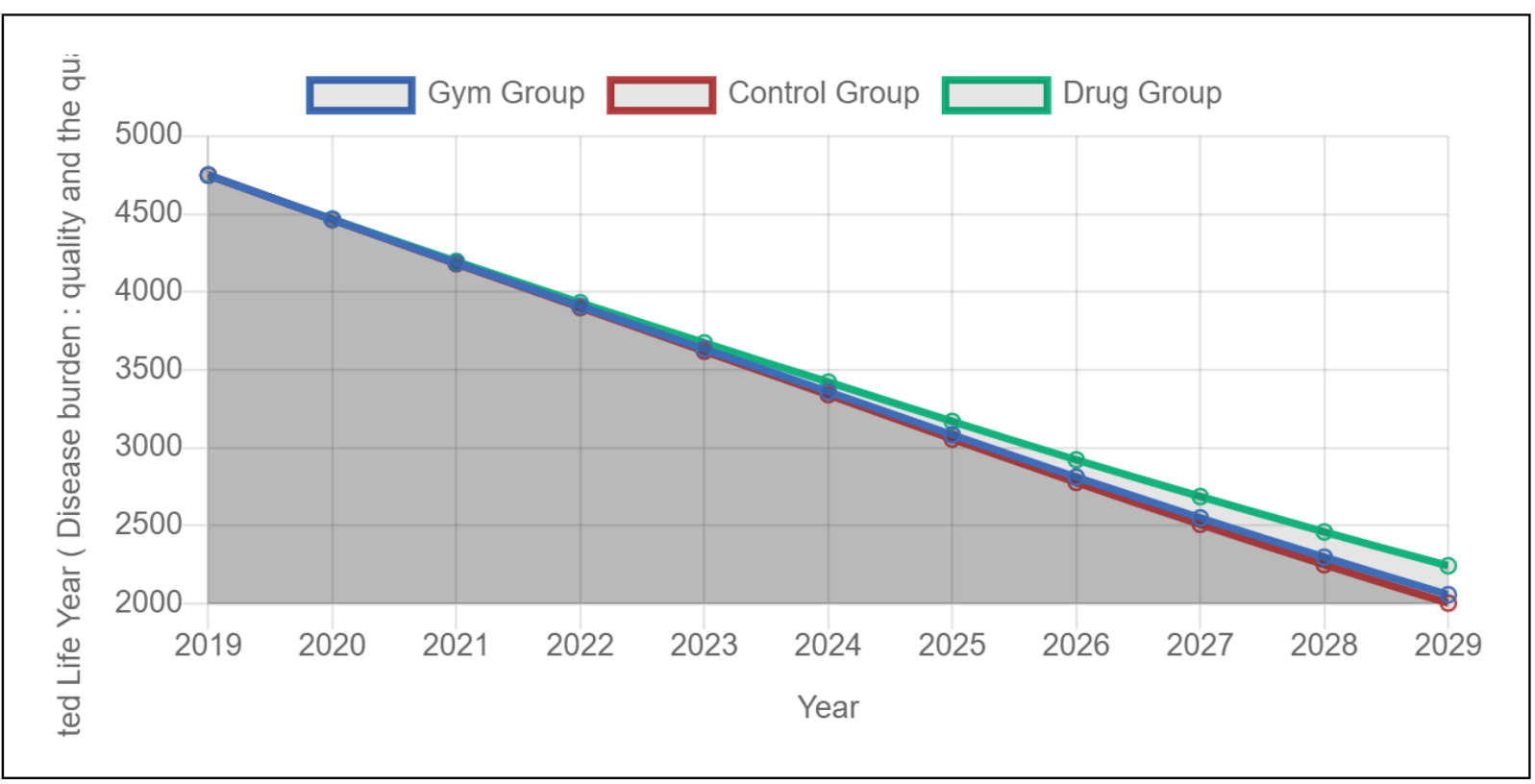

Figure 24 Plot of Total Quality-Adjusted Life-Years Across for the Three Participating Groups 


\section{A.1.1.22 Total Annual Cost of Remaining in the Current State of the Disease Across the Groups}

StateCost : Cost of remaining in the current state of disease.

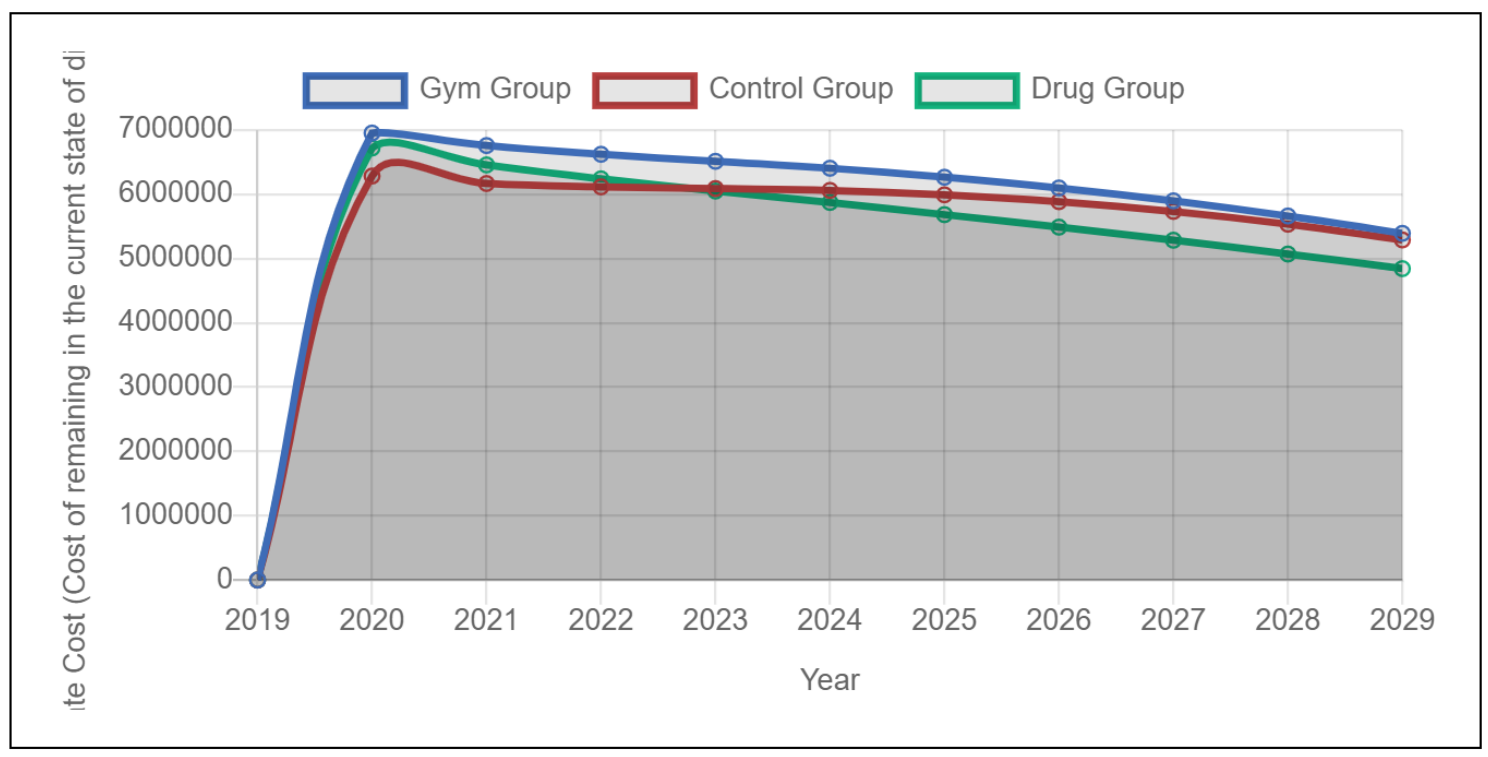

Figure 25 Plot of Average Annual Cost of Remaining in the Current State of The Disease for the Three Participating Groups 


\section{A.1.1.23 Total Costs Across All Groups}

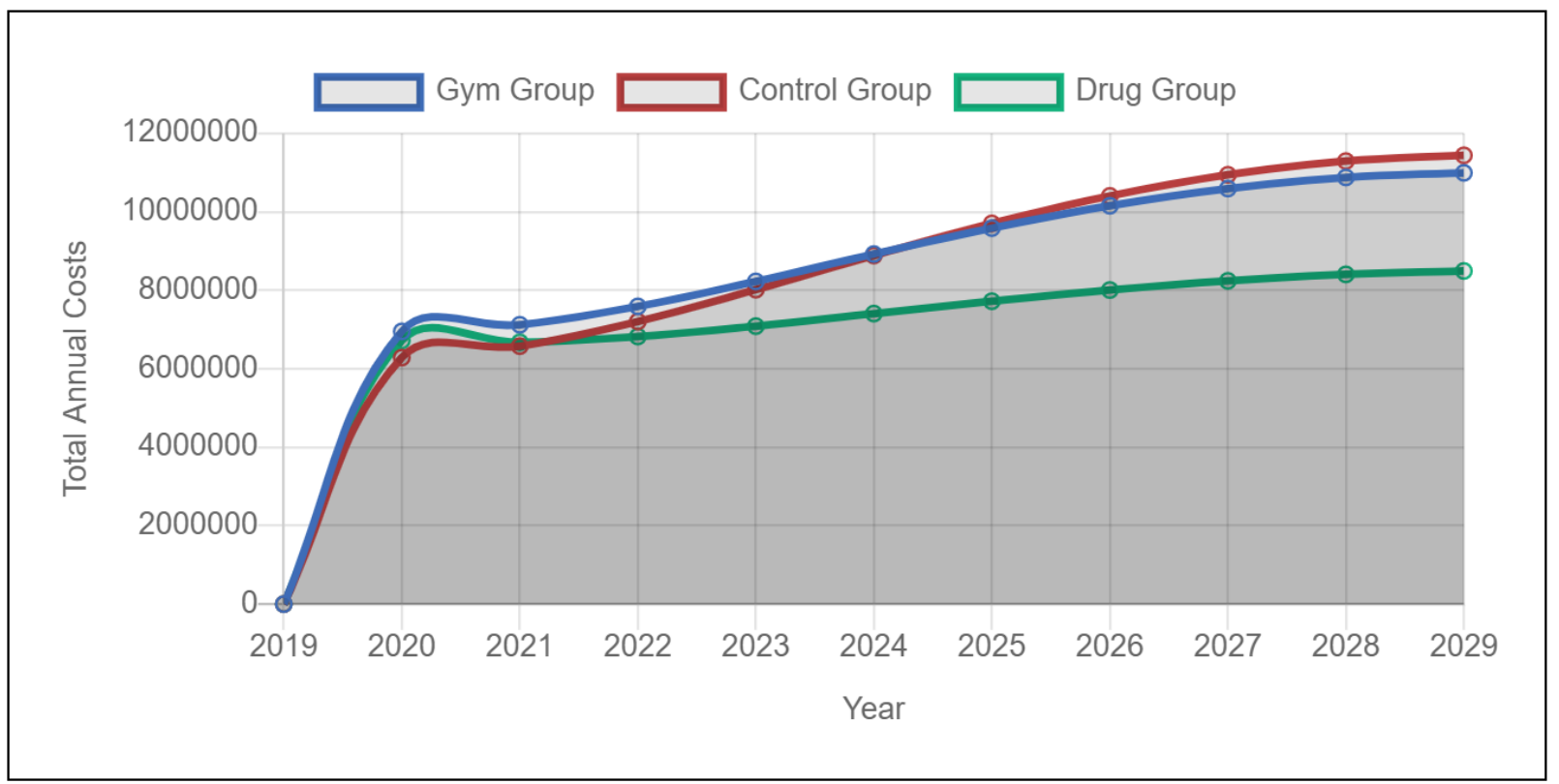

Figure 26 Plot of the Annual Total Costs of the Three Participating Groups

\section{A.1.1.24 Total Deaths Across All Groups}

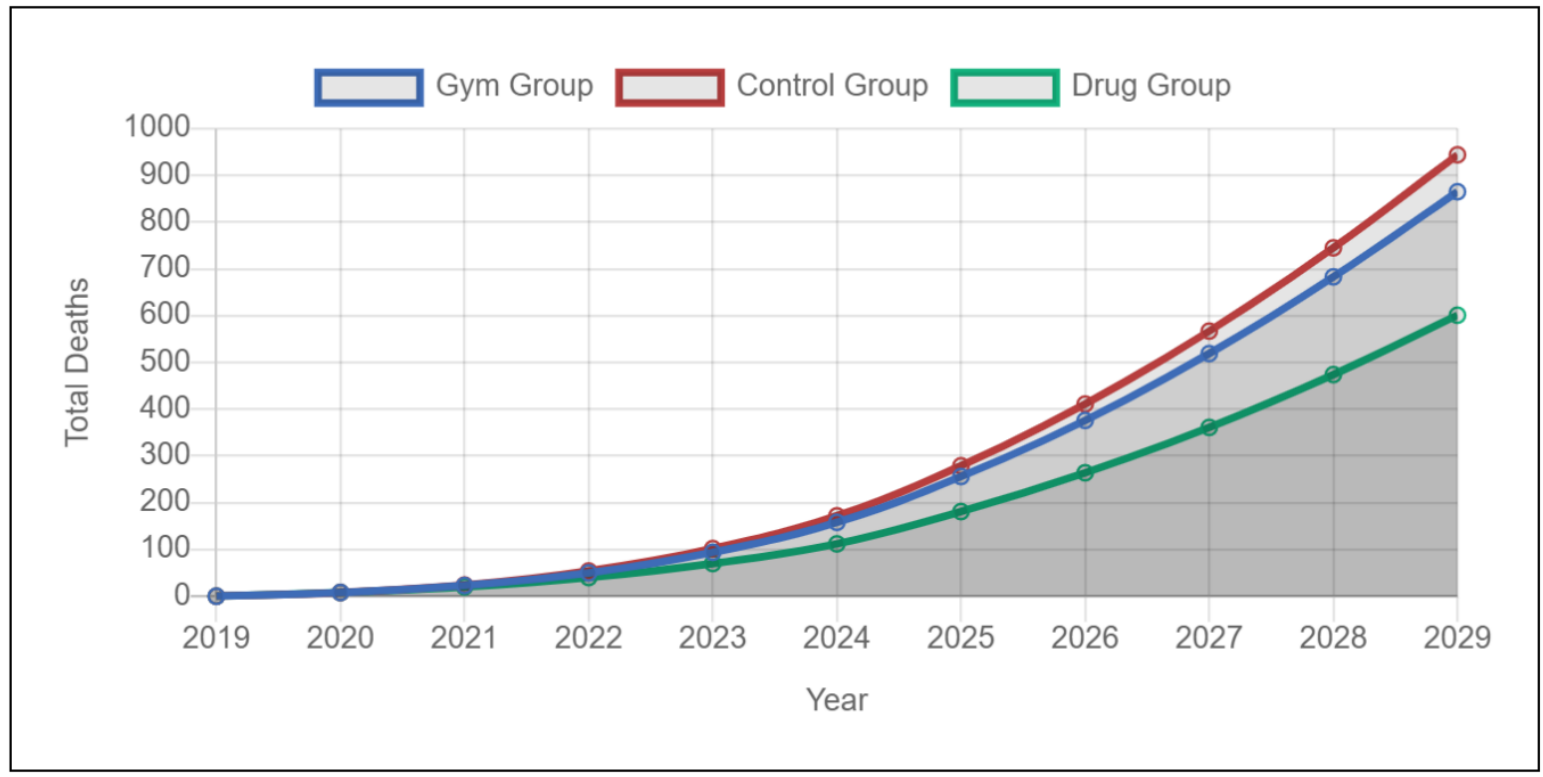

Figure 27 Plot of The Accumulated Deaths per Group Over the Years 


\section{Monte Carlo Simulation}

In the second stage of this simulation, we performed a 1,000 simulation through Monte Carlo Simulation model to check for the robustness of the Markov Model's results. Table 7 demonstrates the results of this simulation on both a group and individual basis.

\begin{tabular}{|llllllll|}
\hline Group Name & LE & LYs & QALE & QALYs & StateCost & TotalCost & TransitionCost \\
\hline Gym Group & $51,781.94$ & $39,776.66$ & $49,211.29$ & $37,906.08$ & $\$ 62,071,605.16$ & $\$ 92,509,907.15$ & $\$ 30,438,301.99$ \\
\hline Gym Group Per Patient & 10.36 & 7.96 & 9.84 & 7.58 & $\$ 12,414.32$ & $\$ 18,501.98$ & $\$ 6,087.66$ \\
\hline Control Group & $51,513.61$ & $39,608.73$ & $48,860.46$ & $37,682.63$ & $\$ 57,909,566.48$ & $\$ 91,643,041.93$ & $\$ 33,733,475.46$ \\
\hline Control Group Per Patient & 10.3 & 7.92 & 9.77 & 7.54 & $\$ 11,581.91$ & $\$ 18,328.61$ & $\$ 6,746.70$ \\
\hline Drug Group & $52,845.92$ & $40,440.87$ & $50,619.90$ & $38,800.17$ & $\$ 57,330,616.29$ & $\$ 75,391,490.98$ & $\$ 18,060,874.69$ \\
\hline Drug Group Per Patient & 10.57 & 8.09 & 10.12 & 7.76 & $\$ 11,466.12$ & $\$ 15,078.30$ & $\$ 3,612.17$ \\
\hline
\end{tabular}

Table 7 Results of the 1,000 simulations through Monte Carlo Simulation 


\section{Discussion of The Simulation Results}

According to the first result of the simulation demonstrated in Figure 22, the medication (drug) group has the most number of individuals in an asymptomatic state of the disease compared to the rest of the sample groups. This trend essentially means that in this group, we have more percentage of people feeling well. In the Gym group, even though not as good as medication group. However, the group is still better performing in achieving healthier individuals compared to our control group.

In the plot, displayed in Figure 23, we observe a pattern in which the individuals in the control group are falling sick and entering a progressive state of the T2D in more numbers compared to the Gym and Medication Group. Medication group, on the other hand, due to a higher compliance rate, can outperform the rest of the group and have a lower percentage of the individuals within a progressive state of the disease.

Figure 24 demonstrates the overall increased quality-adjusted life-years per group. Referring to Table 8 in the appendices section, the medication group is displaying a slightly higher qualityadjusted life-years. This result means that the individuals within the medication group are having more top quality of life compared to the gym and control group. The reason behind the gym group not having as much significance as the medication is the lack of adherence of its participants.

In Figure 25, the control group's annual total costs are cheaper on the State-Cost basis, and it is because we are not integrating any interventions in this group. However, based on Figure 26 which demonstrates the total annual costs associated with each group, three years into the prevention program, and the overall total costs of the control group start to rise and surpass the other two groups. This rise is primarily because individuals in the control group seem to have a more unstable 
disease state which is shifting more often, causing the increased jump in their annual Transition Costs (For instance, Hospitalization) and Total Costs. Individuals in the Gym group and Drug group have a more stable life, and their disease is under better control, promoting a better quality of life.

Figure 27 and Table 8 demonstrate a frightening difference in accumulated deaths between the three groups. At the end of the year 2029, 945 from 5,000 participants of the control group are expected to lose their lives due to the disease. This loss means that 945 individuals will not make it to their $50^{\text {th }}$ birthday due to T2D. In the medication group, we have far fewer deaths as this number is only 602 . This number of deaths means that total deaths in the medication group are only $63 \%$ to that of the control group, and this brings up an important point about social value. By the end of the year 2029, in the medication group, we would have saved almost 243 individuals' lives.

As stated by the results of the Monte Carlo Simulation demonstrated in Table 7, the average total cost of a patient living in GTA in control group is CAD 18,328.60 annually while the medication group will only face CAD 15,078.29 each year on average. However, the Gym group is the most expensive of our three groups based on Total Annual Costs for each individual, as each individual in this group will face an annual expense of $\$ 18,501.98$. Gym group has a slightly higher cost compared to the control group.

Nevertheless, According to Table 7, both Gym and Medication groups promote the QALY, QALE, LYs and LE while the control group suffers due to disease burden against their quality-adjusted life expectancy. 
In conclusion, any of the Medication or Gym group are good moral and social options, while medication intervention is the most valuable route in both monetary and social value. This intervention promotes quality of life, lowers death rates, increases the life expectancy and reduces the annual costs. 


\section{Discussion}

The primary purpose of this investigation was to design a software model that can enhance and facilitate future research in the field of healthcare and primarily chronic illnesses. During this investigation, we asked the following question:

- How Information Technology can help in healthcare to develop cost-effective prevention strategies for Type-2 Diabetes?

To answer the question above, we initially conducted a literature review in the field of healthcare

in Canada, and later we proposed the development of a software model which can help facilitate the study of health economics. We performed a reusability test using C.K reusability metrics on the developed simulation software design and architecture, and the results suggested that the proposed and developed software is maintainable, reusable and extendable.

Finally, we used the simulation software to simulate an RCT across three diabetic sample groups in the Greater Toronto Area and investigated the results in a separate section.

The results of the simulation suggested that prevention using medication, due to mainly its high adherence rates compared to prescription exercise is more successful and beneficial in terms of being cost effective and promoting quality of life compared to the gym and control groups. 


\section{Conclusion}

The primary purpose of this thesis was to understand the nature of chronic diseases and primarily Type 2 Diabetes and the current practices and prevention strategies available to reduce the burden of this disease.

After understanding what type of challenges scientists in Canada are facing when testing the nature of Type 2 Diabetes in Canadian settings, we proposed a simulation software and developed the first software milestone.

We later ran our first simulation to test the software and discussed our first results generated by the software running a Markov Model along with a Monte Carlo Simulation. As results suggested the cost-effectiveness of the prevention strategies, we hope that in future investigators use this software to compare different healthcare strategies and promote a healthier society through an efficient and cost-saving approach which benefits both the patients and the healthcare organizations.

In the following sections will discuss the contributions, limitations and recommendations for future research.

\section{Recommendation}

We recommend future researchers to consider the environmental factors which can affect the outcome of the models. These elements could be the income level of the families, type of commute to work, the industry the individuals work in, and the highest level of education.

As this system passes the reusability test, we can recommend this work to be the groundwork for future developments and researches and introduce more variables which they believe can affect 
the outcomes of the studies, into the models. Extending the software package by adding further simulation methods and algorithms into it can certainly help improve the accuracy of the simulations. 


\section{Contributions}

The main contribution of this research is the preparation of the tool that can be reused by many scientists around the world to test their hypothesis without having to code a model over and over.

The second contribution is that if implemented nationally, this simulation software can be used to accelerate and increase the number of studies conducted in Canadian healthcare settings.

The patterns used in this software application allow for reusability, maintainability and scalability and as a result, this can provide the groundwork for future software developers and scientists to improve and scale the software and introduce more simulation models to it without having to redesign an entire application.

\section{Limitations}

The application of the software proposed and developed as part of this thesis needs further testing by scientists and doctors, primarily in the field of chronic illnesses. The scope and area of this thesis only allowed us to academically prepare this paper, which has the potential of translating into a real-world tool.

Hosting the web application on a hosting environment suitable for testing could facilitate the process of development as we could invite experts to test the system and hear their feedback about how it could be further improved. 


\section{Appendices}

\section{A.1 Ndepend Query Codes}

\section{A.1.1 NDepend 2019 Query Scripts}

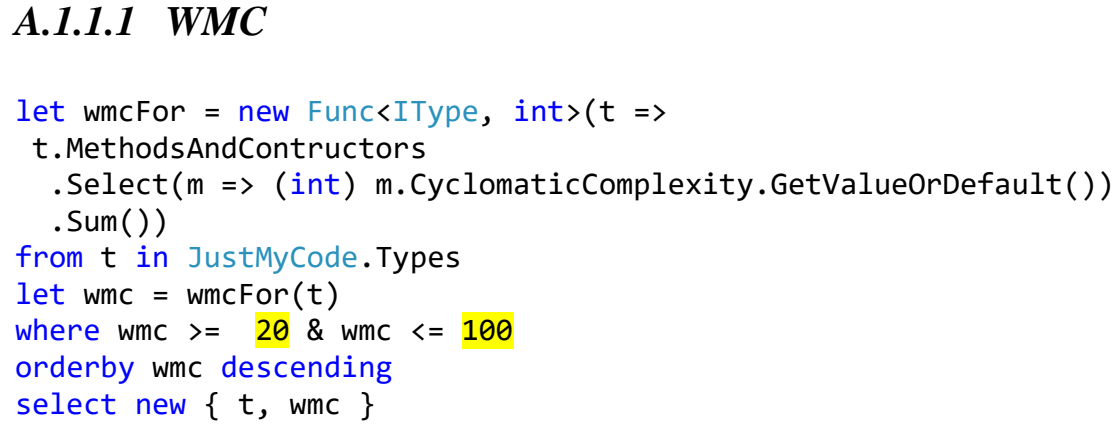

\section{A.1.1.2 RFC}

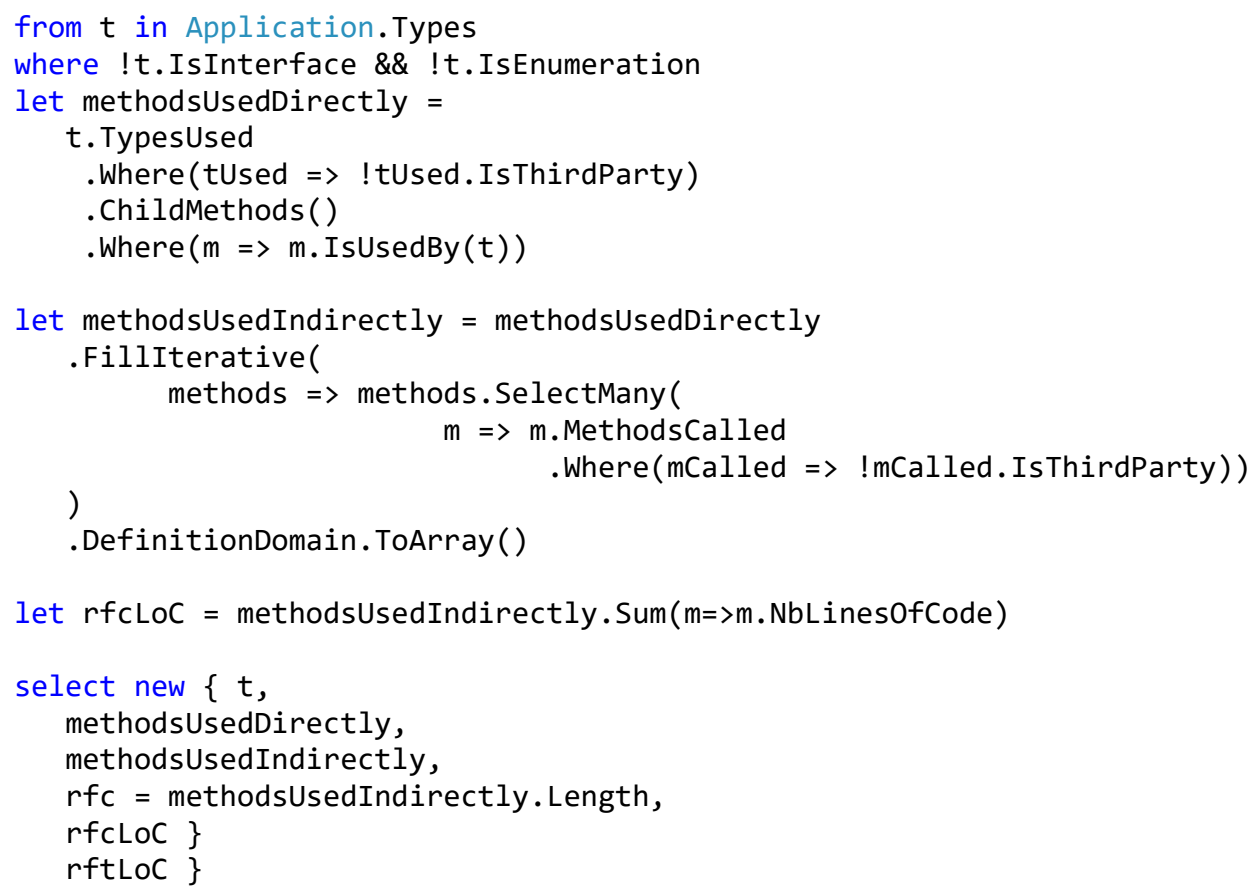

\section{A.1.1.3 DIT}

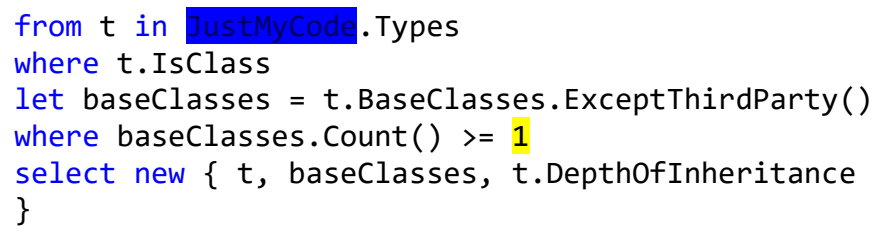




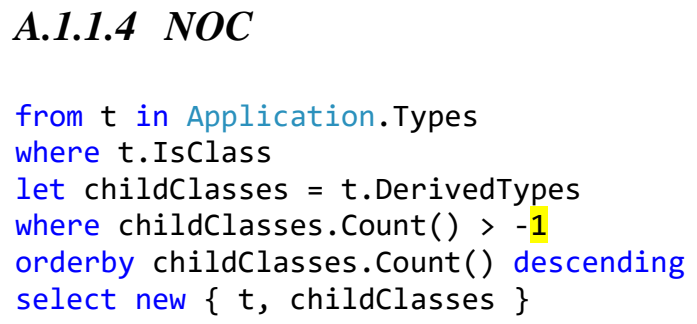

\section{A.1.1.5 CBO}

from $t$ in Application.Types

let $\mathrm{CBO}=\mathrm{t}$. TypesUsed.ExceptThirdParty ()

orderby СВO .Count() descending

select new $\{t, C B O\}$

\section{A.1.1.6 LCOM}

This section has no additional script, as the NDepend v2019 extension for Visual Studio 2019 has generated this view. 


\section{A.2 Markov Model Results for All Groups}

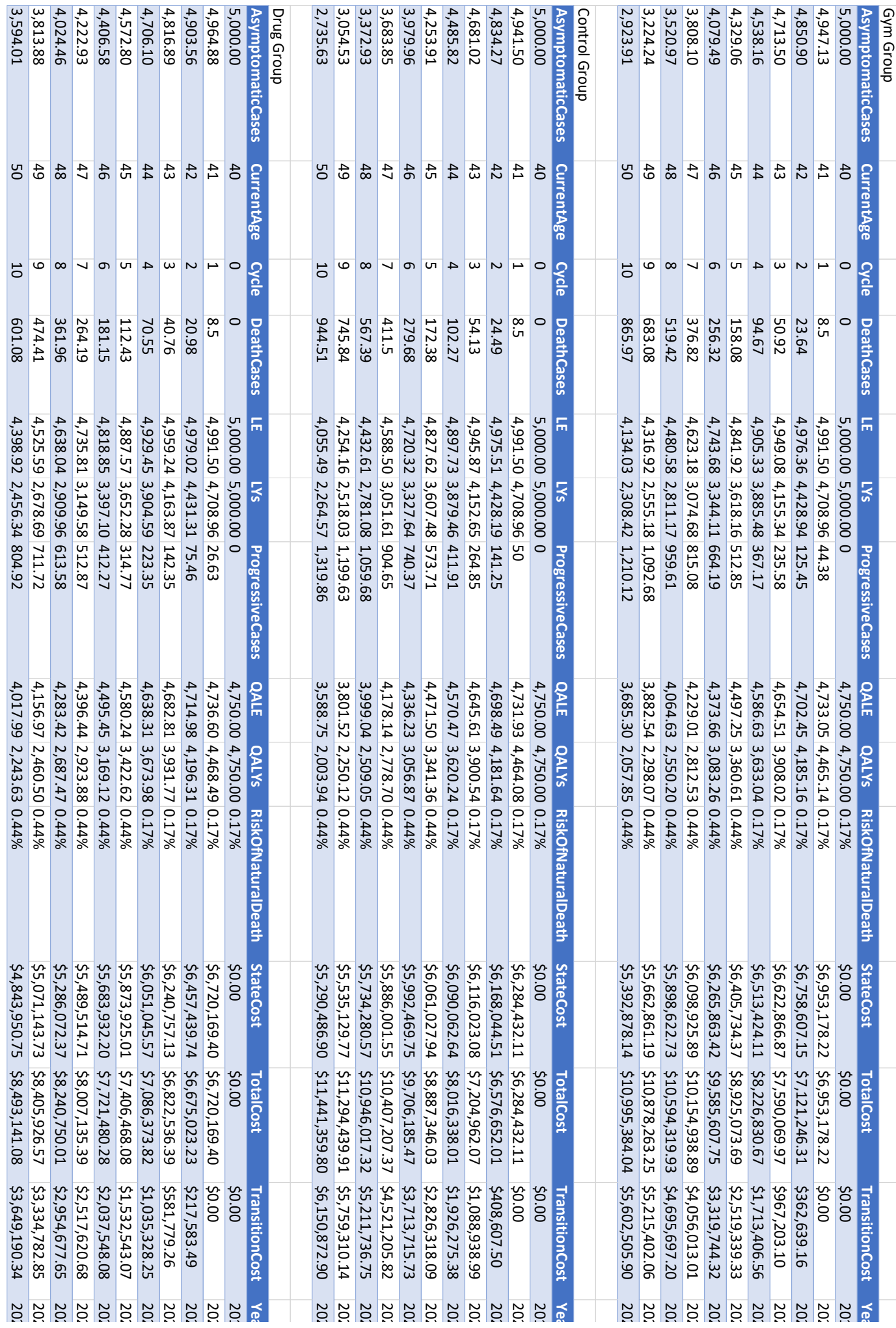

Table 8 Results of the Markov Model 


\section{References}

Allingham, M. (2002). Choice theory : a very short introduction. Oxford University Press.

Anderson, J. M. (2012). Achievable Cost Saving and Cost-Effective Thresholds for Diabetes Prevention Lifestyle Interventions in People Aged 65 Years and Older: A Single-Payer Perspective. Journal of the Academy of Nutrition and Dietetics, 112(11), 1747-1754. https://doi.org/10.1016/j.jand.2012.08.033

Attema, A. E., Brouwer, W. B. F., \& Claxton, K. (2018). Discounting in Economic Evaluations. PharmacoEconomics, 36(7), 745-758. https://doi.org/10.1007/s40273-018-0672-z

Baker, M. K., Simpson, K., Lloyd, B., Bauman, A. E., \& Singh, M. A. F. (2011). Behavioral strategies in diabetes prevention programs: A systematic review of randomized controlled trials. Diabetes Research and Clinical Practice, 91(1), 1-12. https://doi.org/10.1016/j.diabres.2010.06.030

Bang, H., \& Zhao, H. (2014). Cost-effectiveness analysis: a proposal of new reporting standards in statistical analysis. Journal of Biopharmaceutical Statistics, 24(2), 443-460. https://doi.org/10.1080/10543406.2013.860157

Bank of Canada. (n.d.). Inflation Calculator. Retrieved from https://www.bankofcanada.ca/rates/related/inflation-calculator/

Bilandzic, A., \& Rosella, L. (2017). The cost of diabetes in Canada over 10 years: applying attributable health care costs to a diabetes incidence prediction model. Health Promotion and Chronic Disease Prevention in Canada: Research, Policy and Practice, 37(2), 49-53. Retrieved from http://www.ncbi.nlm.nih.gov/pubmed/28273040 
Bleichrodt, H., \& Quiggin, J. (1999). Life-cycle preferences over consumption and health: When is cost-effectiveness analysis equivalent to cost-benefit analysis? Journal of Health Economics, 18(6), 681-708. https://doi.org/10.1016/S0167-6296(99)00014-4

Briggs, A. H., Claxton, K., \& Sculpher, M. J. (2006). Decision modelling for health economic evaluation. Oxford University Press.

CachéQuality. (2019). Depth of Inheritance Tree. Retrieved August 27, 2019, from https://www.cachequality.com/docs/metrics/depth-inheritance-tree

Canadian Agency for Drugs and Technologies in Health. (2018). How Much Do Diabetes Drugs Cost? Retrieved from https://cadth.ca/tools/how-much-do-diabetes-drugs-cost

Canadian Diabetes Association. (2019). Physical activity - Diabetes Canada. Retrieved August 28, 2019, from https://www.diabetes.ca/managing-my-diabetes/tools---resources/physicalactivity

Canadian Institute for Health Information. (2007). Health Care in Canada 2007. Retrieved from www.cihi.ca

Canadian Institute for Health Information. (2018). National Health Expenditure Trends, 1975 to 2017: Data Tables - Series E1.

Chidamber, S. R., \& Kemerer, C. F. (1994). A metrics suite for object oriented design. IEEE Transactions on Software Engineering, 20(6), 476-493. https://doi.org/10.1109/32.295895

Chronic Disease Prevention Alliance of Canada. (2017). Chronic Disease Prevention Alliance of Canada 2018 pre-budget submission to the House of Commons Standing Committee on $\begin{array}{lll}\text { Finance. } & \text { 2014-2017. } & \text { Retrieved }\end{array}$ http://www5.statcan.gc.ca/cansim/a05?lang=eng\&id=1020561. 
Dan Abramov. (2015). Redux - A Predictable State Container for JS Apps. Retrieved August 27, 2019, from https://redux.js.org/

Esmail, N. (2017). Leaving Canada for medical care. Fraser Forum, July/Augus(June), 1-7.

$\begin{array}{ll}\text { Retrieved } & \text { from }\end{array}$ http://media.proquest.com.myaccess.library.utoronto.ca/media/pq/classic/doc/2749238061/f $\mathrm{mt} / \mathrm{pi} / \mathrm{rep} / \mathrm{NONE} ? \mathrm{hl}=\& \mathrm{cit} \% 3$ Aauth=Esmail\%2C + Nadeem $\&$ cit\%3Atitle=Leaving + Canada $+\mathrm{f}$ or+medical+care+2011\&cit\%3Apub=Fraser+Forum\&cit\%3Avol=\&cit\%3Aiss=\&cit\%3Apg $=18 \& \operatorname{cit} \% 3$ Adate $=\mathrm{Jul}$

European Patients' Academy. (2015). Life Years Gained - EUPATI. Retrieved August 27, 2019, from https://www.eupati.eu/glossary/life-years-gained/

Facebook Inc. (2019). React - A JavaScript library for building user interfaces. Retrieved August 27, 2019, from https://reactjs.org/

Friday, L. (2018). Universal Health Care in Canada: A Colossal Government Failure | Mises Wire. Retrieved April 7, 2019, from https://mises.org/wire/universal-health-care-canada-colossalgovernment-failure

Government of Canada. (2017). Diabetes in Canada - Canada.ca. Retrieved August 28, 2019, from https://www.canada.ca/en/public-health/services/publications/diseases-conditions/diabetescanada-highlights-chronic-disease-surveillance-system.html

H.M, M., \& Nandakumar, D. (2016). Constructing Relationship Between Software Metrics and Code Reusability in Object Oriented Design. International Journal of Advanced Computer Science and Applications, 7(2). https://doi.org/10.14569/IJACSA.2016.070258

Herman, W. H. (2015). The cost-effectiveness of diabetes prevention: results from the Diabetes 
Prevention Program and the Diabetes Prevention Program Outcomes Study. Clinical Diabetes and Endocrinology, 1(1), 9. https://doi.org/10.1186/s40842-015-0009-1

Herman, W. H. (2017). The global agenda for the prevention of type 2 diabetes. Nutrition Reviews, 75(suppl 1), 13-18. https://doi.org/10.1093/nutrit/nuw034

Hoogendoorn, S. W., Rutten, G. E. H. M., Hart, H. E., de Wolf, C., \& Vos, R. C. (2019). A simple to implement and low-cost supervised walking programme in highly motivated individuals with or at risk for type 2 diabetes: An observational study with a pre-post design. Preventive Medicine Reports, 13, 30-36. https://doi.org/10.1016/j.pmedr.2018.11.003

Humber River Hospital. (2019). Fitness Centre - Humber River Hospital. Retrieved August 28, 2019, from https://www.hrh.ca/fitnesscentre/

Huzumi, N., Mao, Z., Kasi, P., \& Zhe, W. (2008). An empirical study on software reuse. Proceedings - International Conference on Computer Science and Software Engineering, CSSE 2008, 6(5), 509-512. https://doi.org/10.1109/CSSE.2008.1661

Icks, A., Rathmann, W., Haastert, B., Gandjour, A., Holle, R., John, J., \& Giani, G. (2007). Clinical and cost-effectiveness of primary prevention of Type 2 diabetes in a 'real world' routine healthcare setting: model based on the KORA Survey 2000. Diabetic Medicine, 24(5), 473480. https://doi.org/10.1111/j.1464-5491.2007.02108.x

Johansson, N., Löfgren, A., \& Olsson, C. M. (2009). Designing for Extensibility: An action research study of maximizing extensibility by means of design principles Designing for extensibility. Retrieved from http://www.gnu.org/

Kaelbling, L. P., Littman, M. L., \& Cassandra, A. R. (1998). Planning and acting in partially observable stochastic domains. Artificial Intelligence, 101(1-2), 99-134. 
https://doi.org/10.1016/S0004-3702(98)00023-X

Li, R., Zhang, P., Barker, L. E., Chowdhury, F. M., \& Zhang, X. (2010). Cost-Effectiveness of Interventions to Prevent and Control Diabetes Mellitus: A Systematic Review. Diabetes Care, 33(8), 1872-1894. https://doi.org/10.2337/dc10-0843

Li, T., Wan, X., Ma, J., \& Wu, B. (2018). Cost-Effectiveness of Primary Prevention with Statin Treatment for Chinese Patients with Type 2 Diabetes. Advances in Therapy, 35(12), 22142223. https://doi.org/10.1007/s12325-018-0823-9

Macedo, A., Baranauskas, J. A., \& Bulcão-Neto, R. (2018, September 26). The Evolution of a Healthcare Software Framework: Reuse, Evaluation and Lessons Learned. 1043-1051. https://doi.org/10.15439/2018F173

Marinho, F. S., Moram, C. B. M., Rodrigues, P. C., Leite, N. C., Salles, G. F., \& Cardoso, C. R. L. (2018). Treatment adherence and its associated factors in patients with type 2 diabetes: Results from the Rio de Janeiro type 2 diabetes cohort study. Journal of Diabetes Research, 2018. https://doi.org/10.1155/2018/8970196

Microsoft Corporation. (2019a). Overview of ASP.NET Core MVC. Retrieved August 27, 2019, from https://docs.microsoft.com/en-us/aspnet/core/mvc/overview?view=aspnetcore- 2.2

Microsoft Corporation. (2019b). Visual Studio IDE, Code Editor, Azure DevOps, \&amp; App Center - Visual Studio. Retrieved August 27, 2019, from https://visualstudio.microsoft.com/

Mijač, M., \& Stapic, Z. (2015). Reusability Metrics of Software Components: Survey. https://doi.org/10.13140/RG.2.1.3611.4642

Ministry of Health and Long-Term Care - Government of Ontario. (2012). Diabetes : Strategies for Prevention - Ministry Reports - Publications - Public Information - MOHLTC. Retrieved 
from

http://www.health.gov.on.ca/en/common/ministry/publications/reports/diabetes/diabetes.asp $\mathrm{X}$

Morisio, M., Ezran, M., \& Tully, C. (2002). Success and failure factors in software reuse. IEEE Transactions on Software $\quad$ Engineering, $\quad$ 340-357. https://doi.org/10.1109/TSE.2002.995420

NCCID. (2015). Understanding Summary Measures Used to Estimate the Burden of Disease All about HALYs, DALYs and QALYs. Retrieved from https://nccid.ca/wpcontent/uploads/sites/2/2015/03/GBD_Factsheet_FINAL_E.pdf

Neumann, A., Lindholm, L., Norberg, M., Schoffer, O., Klug, S. J., \& Norström, F. (2017). The cost-effectiveness of interventions targeting lifestyle change for the prevention of diabetes in a Swedish primary care and community based prevention program. The European Journal of Health Economics, 18(7), 905-919. https://doi.org/10.1007/s10198-016-0851-9

Node.js Foundation. (2019). About Node.js. Retrieved August 27, 2019, from https://nodejs.org/en/about/

Padhy, N., Singh, R. P., \& Satapathy, S. C. (2018). Software reusability metrics estimation: Algorithms, models and optimization techniques. Computers and Electrical Engineering, 69, 653-668. https://doi.org/10.1016/j.compeleceng.2017.11.022

Palmer, A. J., \& Tucker, D. M. D. (2012). Cost and clinical implications of diabetes prevention in an Australian setting: A long-term modeling analysis. Primary Care Diabetes, 6(2), 109-121. https://doi.org/10.1016/j.pcd.2011.10.006

Park, J., \& Peters, P. A. (2014). Mortality from diabetes mellitus, 2004 to 2008: A multiple- 
causeof-death analysis. Health Reports, 25(3), 12-16.

Passey, M. E., Shrestha, R. N., Bertram, M. Y., Schofield, D. J., Vos, T., Callander, E. J., ... Kelly, S. J. (2012). The impact of diabetes prevention on labour force participation and income of older Australians: an economic study. BMC Public Health, 12(1), 16. https://doi.org/10.1186/1471-2458-12-16

Public Health Agency of Canada. (2013). Preventing chronic disease strategic plan 2013-2016. Retrieved from http://publications.gc.ca/site/eng/9.697763/publication.html

RADU, L. D. (2018). An Ecological View on Software Reuse. Informatica Economica, 22(3/2018), 75-85. https://doi.org/10.12948/issn14531305/22.3.2018.07

Schwarz, P., Lindström, J., Kissimova-Scarbeck, K., Szybinski, Z., Barengo, N., Peltonen, M., ... DE-PLAN project. (2008). The European Perspective of Type 2 Diabetes Prevention: Diabetes in Europe - Prevention Using Lifestyle, Physical Activity and Nutritional Intervention (DE-PLAN) Project. Experimental and Clinical Endocrinology \& Diabetes, 116(03), 167-172. https://doi.org/10.1055/s-2007-992115

Selvarani, R., Gopalakrishnan Nair, T. R., Ramachandran, M., \& Prasad, K. (2009). Software metrics evaluation based on entropy. In Handbook of Research on Software Engineering and Productivity Technologies: Implications of Globalization (pp. 139-151). https://doi.org/10.4018/978-1-60566-731-7.ch011

Solanas, A., Weber, J. H., Bener, A. B., van der Linden, F., \& Capilla, R. (2017). Recent Advances in Healthcare Software: Toward Context-Aware and Smart Solutions. IEEE Software, 34(6), 36-40. https://doi.org/10.1109/MS.2017.4121202

Statistics Canada. (2011). Canada Year Book: Population and Demography. 352-365. 
Statistics Canada, G. of C. (2009). Life expectancy. Retrieved August 27, 2019, from https://www150.statcan.gc.ca/n1/pub/82-229-x/2009001/demo/lif-eng.htm

Statistics Canada, G. of C. (2019). Diabetes, by age group. Retrieved August 28, 2019, from https://www150.statcan.gc.ca/t1/tbl1/en/tv.action?pid=1310009607

Sussman, J. B., Kent, D. M., Nelson, J. P., \& Hayward, R. A. (2015). Improving diabetes prevention with benefit based tailored treatment: risk based reanalysis of Diabetes Prevention Program. BMJ, 350(feb19 2), h454-h454. https://doi.org/10.1136/bmj.h454

Tanuseputro, P., Wodchis, W. P., Fowler, R., Walker, P., Bai, Y. Q., Bronskill, S. E., \& Manuel, D. (2015). The Health Care Cost of Dying: A Population-Based Retrospective Cohort Study of the Last Year of Life in Ontario, Canada. PLOS ONE, 10(3), e0121759. https://doi.org/10.1371/journal.pone.0121759

Walter, J.-C., \& Barkema, G. T. (2015). An introduction to Monte Carlo methods. Physica A: Statistical Mechanics and Its Applications, 418, $\quad 78-87$. https://doi.org/10.1016/J.PHYSA.2014.06.014

Weber-Jahnke, J. H., Price, M., \& Williams, J. (2013). Software engineering in health care: Is it really different? and how to gain impact. 2013 5th International Workshop on Software Engineering in Health Care, SEHC 2013 - $\quad$ Proceedings, 1-4. https://doi.org/10.1109/SEHC.2013.6602469

WebMD. (2019). Atorvastatin Oral : Uses, Side Effects, Interactions, Pictures, Warnings \&amp; Dosing - WebMD. Retrieved April 8, 2019, from https://www.webmd.com/drugs/2/drug841/atorvastatin-oral/details

William C. Shiel. (2018). Medical Definition of Quality adjusted life year (QALY). Retrieved 
April 8, 2019, from https://www.medicinenet.com/script/main/art.asp?articlekey=5167

World Population Review. (2019). Toronto Population 2019. Retrieved August 28, 2019, from http://worldpopulationreview.com/world-cities/toronto-population/

ZEN PROGRAM LTD. (2019). NDepend Product Features. Retrieved from https://www.ndepend.com/ 